\title{
Vapor-liquid equilibrium and excess properties of the binary mixtures formed by ethyl isobutyrate and n-alkanols
}

Najla Ben Mahdoui ${ }^{\dagger \ddagger}$, Raouia Abidi ${ }^{\dagger \ddagger}$, Héctor Artigas ${ }^{\ddagger}$, Monia Hichri ${ }^{\dagger, *}$, Carlos Lafuente ${ }^{\ddagger}$

‡ Departamento de Química Física, Facultad de Ciencias, Universidad de Zaragoza, 50009 Zaragoza, Spain

† Université de Tunis EL Manar, Faculté des Sciences, Laboratoire des Matériaux, Cristallochimie et Thermodynamique Appliquée, LR15ES01, Département de Chimie, 2092 Tunis, Tunisia

*Corresponding author. Tel: 0021698559305, E-mail address: monia.hichri@fst.utm.tn 
Abstract: This contribution reports densities together with the corresponding excess molar volumes, and excess molar enthalpies of the binary mixtures formed by ethyl isobutyrate and n-alkanols (from methanol to 1-butanol) at two temperatures (303.15 and 323.15) $\mathrm{K}$ and at atmospheric pressure ( $p=0.1 \mathrm{MPa}$ ). These excess properties were correlated with composition using the Redlich-Kister equation. Excess molar volumes and enthalpies are positive, except the excess molar volumes for the mixture ethyl isobutyrate and methanol. Furthermore, the vapor-liquid equilibrium data for these mixtures at different experimental conditions have been also presented. Both the isothermal VLE at two temperatures (303.15 and 323.15) $\mathrm{K}$ and isobaric VLE at two pressures (40.000 and 101.325) kPa were measured. Some of the systems exhibit azeotropic points. The VLE data were found thermodynamically consistent. From experimental data the activity coefficients along with excess Gibbs function (isothermal) and reduced excess Gibbs functions (isobaric) were obtained and correlated with composition using the Wilson equation. These excess Gibbs function and reduced excess Gibbs functions were found positive. Finally, we have used our experimental VLE data to check the reliability of modified UNIFAC predictions.

Keywords: Alkanols, Density, Enthalpy of mixing, Ethyl isobutyrate, Vapor-liquid equilibrium. 


\section{Introduction}

Flavors and fragrances are faithful companions in daily life [1-4]. Several of them have an ester as major component [5-8]. However, the medium in which the flavor is found needs to preserve the quality and the characteristics of the molecule responsible for the scent. Therefore, the study of thermophysical properties of these esters and of its mixtures are of great importance for the design of chemical processes in which the esters are implicated. In this sense, ethyl isobutyrate is a flavoring substance $[9,10]$ which exists in banana, apple, wine grape, so can be found in some drinks.

In this work, we report experimental results (densities, mixing enthalpies and vaporliquid equilibrium) for the binary systems: ethyl isobutyrate + n-alkanol (methanol, ethanol, 1-propanol or 1-butanol). Densities and mixing enthalpies were measured at two temperatures (303.15 and $323.15 \mathrm{~K}$ ) and at atmospheric pressure (0.1 MPa). Vapor-liquid equilibrium of these mixtures was determined in two runs performed at constant temperature (303.15 and $323.15 \mathrm{~K})$ and at constant pressure (40.000 and $101.325 \mathrm{kPa})$. It can be also outlined that the modified UNIFAC [11] was checked using our experimental VLE data.

To our knowledge, the properties presented here of binary mixtures involving ethyl isobutyrate and a normal alcohol at different temperatures have not been measured previously.

\section{Experimental}

Table 1 summarizes the information about the compounds employed in our study. With respect to the water content of the chemicals, it was determined by means of an automatic titrator Crison KF 1S-2B. 
Densities of the samples, pure compounds or mixtures, were determined by means of an Anton Paar DMA 5000 vibrating tube densimeter internally thermostated at $\pm 0.005 \mathrm{~K}$. Calibration procedure can be found elsewhere [12]. The uncertainty of density measurements can be estimated in $2 \cdot 10^{-4} \mathrm{~g} \cdot \mathrm{cm}^{-3}$.

The mixtures were prepared by mass using a Sartorius Semimicro balance CP225-D within $\pm 10^{-5} \mathrm{~g}$. The corresponding estimated uncertainty in the mole fraction of the mixtures is $10^{-4}$.

The thermal effect of the mixing process was registered using a Thermometric 2277 thermal activity monitor, thermostated within $\pm 2 \cdot 10^{-4} \mathrm{~K}$, together with two Shimadzu LC-10ADVP HPLC pumps to supply the liquids. The calorimeter and the pumps were previously calibrated $[13,14]$, in particular the calorimeter was chemically calibrated using the well known heats of mixing of the n-hexane + cyclohexane mixture [15]. From the mixing thermal effect and the flows of the components the excess molar enthalpies at each composition can be easily calculated. The uncertainty in excess molar enthalpies is $1 \%$ while the uncertainty in the mole fractions of the mixtures is 0.001 .

The vapor-liquid equilibrium of the pure compounds and systems at the different experimental conditions (isothermal and isobaric) were measured using a dynamic ebulliometer (Fischer Labodest) with recirculation of both phases provided with a Cottrell pump, this equipment has been previously described [16]. The pressure was measured with an uncertainty of $0.1 \mathrm{kPa}$ by means of a Paroscientific Digiquartz 215A-102 pressure transducer and a Digiquartz 735 display unit, while the temperature was measured with an uncertainty of $0.1 \mathrm{~K}$ using an Automatic Systems Laboratories (model F25) thermometer with a PT100 probeAfter reaching the equilibrium, samples of both liquid and condensed vapor phases were taken. The compositions of these samples were determined by densitometry, using the 
previously obtained density-composition curves, the estimated uncertainty in mole fraction is 0.002 .

Table 2 shows the comparison between our experimental values for the thermophysical properties of the pure compounds and the corresponding literature values [1759]. On the other hand, a graphical comparison between our experimental values and some literature values [60-63] is shown in Fig. 1.

\section{Results and discussion}

There are not previous density data at our working temperatures for ethyl isobutyrate, so no comparison is possible, with respect to experimental vapour pressures and those calculated using the data of Stull [17] the concordance is reasonable with an average deviation equals to $0.176 \mathrm{kPa}$, finally the agreement between our normal boiling point and those of the literature is really good. Regarding to the alkanols the comparison between our experimental and literature values is satisfactory, the higher deviations are presented for the vapour pressures of 1-propanol and 1-butanol, these deviations are around $0.1 \mathrm{kPa}$. In general terms, we can outlined that the deviations between measured and literature values are close to the experimental uncertainties.

The experimental densities together with calculated excess molar volumes for the studied binary mixtures are collected in Table S1 of the Supplementary material, while the excess molar enthalpies are reported in Table S2.

Excess molar volume, $V^{\mathrm{E}}$, can be obtained for each composition of the mixture from the molar masses and densities of the pure components (in the same physical state as the mixture [64]) and densities of the mixtures using standard procedures. On the other hand, as 
we have mentioned above, the excess molar enthalpies at each composition can be obtained from the mixing thermal effect and the corresponding component flows.

Excess molar volumes and excess molar enthalpies have been plotted in Figs. 2 and 3, respectively. Both excess properties have been correlated with composition using the RedlichKister equation [65]:

$$
Y^{E}=x_{1}\left(1-x_{1}\right) \sum_{i} A_{i}\left(2 x_{1}-1\right)^{i}
$$

being $Y^{E}$ the excess property, $x_{1}$ the mole fraction of ethyl isobutyrate, and $A_{\mathrm{i}}$ the fitting parameters. Table 3 reports both Redlich-Kister parameters and standard deviations, $\sigma\left(Y^{\mathrm{E}}\right)$.

The excess molar volumes, $V^{\mathrm{E}}$, are positive over the entire composition range from ethanol to 1-butanol, while for methanol the $V^{\mathbb{E}}$ values are negative. The representation of excess molar volume against composition for all the systems is quite symmetrical. For a given temperature the $V^{\mathrm{E}}$ values follow the sequence: methanol < ethanol < 1-propanol < 1-butanol, that is, the positive contributions to excess molar volume increase with the alkanol length. Moreover, for all the mixtures the excess molar volume increases with temperature, being this increase bigger for the mixture containing ethanol and quite similar for the rest of the systems.

The excess molar enthalpies, $H^{\mathrm{E}}$, are positive for all the binary mixtures. The corresponding $H^{\mathrm{E}}$ plots are not symmetrical, they are shifted to the ethyl isobutyrate rich region. The $H^{\mathrm{E}}$ values at both temperatures follow the same order than the $V^{\mathrm{E}}$ ones: methanol $<$ ethanol $<1$-propanol $<1$-butanol. With respect to the temperature behaviour, $H^{\mathrm{E}}$ increases with temperature for all the systems, in the case of 1-propanol this increase leads to similar $H^{\mathrm{E}}$ values for the mixtures containing 1-propanol and 1-butanol at $T=313.15 \mathrm{~K}$; on the other hand for the system ethyl isobutyrate + methanol the $H^{\mathrm{E}}$ rise is quite higher and noticeable.

The experimental data for vapor-liquid equilibrium $\left(T, p, x_{\mathrm{i}}, y_{\mathrm{i}}\right)$ obtained at both conditions isothermal $(T=303.15$ and $323.15 \mathrm{~K})$ and isobaric $(p=40.000$ and $101.325 \mathrm{kPa})$ 
along with calculated activity coefficients and excess Gibbs functions, $G^{\mathrm{E}}$, or reduced excess Gibbs functions $\left(G^{\mathrm{E}} / \mathrm{R} T\right)$ are listed in Tables S3 to S4 of the supplementary material.

The activity coefficients $\gamma_{i}$ of the components in the liquid phase have been calculated taking into account both the non-ideality of the vapour phase and the variation with pressure of the Gibbs functions of the pure compounds [66]:

$$
\begin{aligned}
& \gamma_{i}=\frac{y_{i} p}{x_{i} p_{i}^{\circ}} \exp \left[\frac{\left(B_{i i}-V_{i}^{\circ}\right)\left(p-p_{i}^{\circ}\right)+\left(1-y_{i}\right)^{2} p \delta_{i j}}{R T}\right] \\
& \delta_{i j}=2 B_{i j}-B_{i i}-B_{j j}
\end{aligned}
$$

where $p$ and $T$ are the pressure and equilibrium temperature, respectively, $R$ is the universal gas constant, $x_{\mathrm{i}}$ and $y_{\mathrm{i}}$ are the liquid and vapour mole fractions of component $i$, respectively, $B_{\mathrm{ii}}$ and $B_{\mathrm{ij}}$ are, respectively, the second virial coefficient of component $i$ and the cross second virial coefficient, finally $V_{i}^{\circ}$ and $p_{i}^{\circ}$ are, respectively, the liquid molar volume and the vapour pressure of the pure compound $i$ at the equilibrium temperature. The values of the virial coefficients were estimated using the Tsonopoulos method $[67,68]$. The liquid molar volumes and vapour pressures of the pure compounds at the temperatures (303.15 and 323.15) K have been measured in our laboratory. These two properties of the components as a function of the temperature for isobaric data were estimated using the Rackett equation [69] for liquid molar volumes, and the Antoine equation for vapor pressures of the components:

$$
\log (p / \mathrm{kPa})=A-\frac{B}{(T / \mathrm{K})+\mathrm{C}}
$$

the parameters of the Antoine equation given in Table S5 of the supplementary material have been taken or calculated from Riddick et al. [70] and Stull [17].

The experimental results were correlated using the Wilson model [71]: based on the following equations: 


$$
\begin{aligned}
& \ln \gamma_{i}=-\ln \left(\sum_{j} x_{j} \Lambda_{i j}\right)+1-\sum_{k} \frac{x_{k} \Lambda_{k i}}{\sum_{j} x_{j} \Lambda_{k j}} \\
& \Lambda_{i j}=\frac{V_{j}^{\circ}}{V_{i}^{\circ}} \exp \left(-\frac{\lambda_{i j}-\lambda_{i i}}{R T}\right)
\end{aligned}
$$

where $V_{i}^{\circ}$ is the liquid molar volume of component $i$ at $T=298.15 \mathrm{~K}$. The $\Lambda_{\mathrm{ij}}$ are the dimensionless model parameters, while $\left(\lambda_{\mathrm{ij}}-\lambda_{\mathrm{ii}}\right)$ are the adjustable Wilson parameters expressed in $\mathrm{J} \cdot \mathrm{mol}^{-1}$. These best parameters have been obtained by minimizing the following objective function [72] that involves experimental and calculated pressures:

$$
F=\sum_{i}\left(\frac{p^{\exp }-p^{c a l}}{p^{\exp }}\right)_{i}^{2}
$$

the calculated pressures, $p^{c a l}$, are obtained through the following expression [73]:

$$
p^{c a l}=\sum_{i} x_{i} \gamma_{i}^{c a l} p_{i}^{\circ} \exp \left[\frac{\left(V_{i}^{\circ}-B_{i i}\right)\left(p-p_{i}^{\circ}\right)-\left(1-y_{i}\right)^{2} p \delta_{i j}}{R T}\right]
$$

Table 4 collects Wilson parameters along with deviation in pressure (isothermal data) or temperature (isobaric data) and average deviation in vapor phase composition. The biggest deviations in pressure and temperature, $\Delta p=0.029 \mathrm{kPa}$ and $\Delta T=0.31 \mathrm{~K}$, respectively, indicate that the correlation for these systems is adequate and that the presented VLE data are reliable. On the other hand, we have tested the thermodynamic consistency of the results using the method suggested by Van Ness et al. [74] and detailed by Fredenslund et al. [75], the experimental data are consistent if $\Delta y<0.01$ and as it can be seen in Table 5, all the systems at the different experimental conditions satisfy this condition. We have used Legendre polynomials for the correlation of activity coefficients. 
The pressure-composition, $p-x_{1}-y_{1}$, and temperature diagrams, $T-x_{1}-y_{1}$, including experimental data and Wilson equation correlation are plotted in Figs. 4-7. Some of the systems present an azeotrope whose coordinates $\left(T_{\mathrm{az}}, p_{\mathrm{az}}, x_{1, \mathrm{az}}\right)$ are given in Table 6 ; the azeotropic coordinates were obtained taking into account that the pressure-composition or temperature diagram must present an extremum and the composition of both phases must be equal, these calculated azeotropic coordinates have been plotted in the corresponding Figs. As the pressure increases, the azeotrope shifts to a lower ethyl isobutyrate composition, the same effect is also observed upon a rise in temperature. On the other hand, for a given pressure or temperature, the increase in the number of carbons in the n-alkanol causes the composition of the azeotropic point to move toward the ethyl isobutyrate rich region.

The excess Gibbs functions and the reduced excess Gibbs functions for all the binary mixtures are graphically represented in Figs. 8 and 9.

For isothermal and isobaric conditions the VLE results present positive deviation from Raoult's law, being the corresponding activity coefficients positive.

The excess Gibbs function, $G^{E}$, show positive values over the entire range of composition for all the studied mixtures with maximum values close to the equimolar composition. The $G^{E}$ values show the string: methanol > ethanol > 1-propanol > 1-butanol. Excess Gibbs function decrease slightly with temperature except for the system containing methanol, for this last system, the maximum $G^{E}$ value increases with rising temperature from 821.3 $\mathrm{J} \cdot \mathrm{mol}^{-1}$ at $T=303.15 \mathrm{~K}$ to $860.5 \mathrm{~J} \cdot \mathrm{mol}^{-1}$ at $T=323.15 \mathrm{~K}$. On the other hand, the entropic contribution to excess Gibbs function, $T S^{E}$, is positive for all the mixtures except for the mixture involving methanol at $T=303.15 \mathrm{~K}$ which entropic contribution is sigmoidal showing a positive value from $x_{1}=0.66$. At a given temperature follows the sequence: 1 butanol $>$ 1-propanol $>$ ethanol $>$ methanol. When the temperature rises the entropic contribution for all the mixtures also increases and becomes positive over the whole 
composition range, at $T=323.15 \mathrm{~K}$ the entropic contribution for the systems containing 1propanol and 1-butanol is quite similar.

The $\left(G^{\mathrm{E}} / \mathrm{RT}\right)$ values of all the studied systems are positive and not too high and decrease with the increase of the pressure, although for the mixture containing methanol this decrease is low. At a given pressure, the reduced excess Gibbs function decreases according to the sequence: methanol $>$ ethanol $>$ 1-propanol $>$ 1-butanol.

The excess molar enthalpy is the most adequate property in order to analyze molecular interactions. Positive contributions to excess molar enthalpy indicate that the molecular interactions are adverse from an energetic point of view, while favorable interactions have a negative contribution to $H^{\mathrm{E}}$. To explain the excess molar enthalpies obtained it must be borne in mind that in the mixing process on one hand the interactions (dipole-dipole interactions in the ester and self-association in the alkanols ) between the pure compounds can be weakened and on the other hand favorable interactions between the mixed components can be established (heteroassociation). Regarding these favorable interactions, ethyl isobutyrate presents hydrogen-bond accepting ability due to the lone-pairs on the $\mathrm{O}$ atoms, therefore it can establish hydrogen bond with alcanols $[76,77]$. The experimental excess molar enthalpy reflects the balance between all these molecular interactions, our systems presents positive and quite high $H^{\mathrm{E}}$ values, being the lowest ones those for the mixture containing methanol because it posses more proton donating ability than higher alkanols [78, 79].

The excess molar volume apart from energetic factors depends on structural factors, that is, $V^{\mathrm{E}}$ also depends on the more or less favorable packing of the molecules of the components in the mixture. In this sense an efficient molecular packing contributes negatively to excess molar volume. For our systems the positive excess molar volumes obtained from ethanol to 1-butanol can be explained by the weakening of dipole-dipole interactions in ethyl isobutyrate as well the dissociation of the alkanols that prevail over the heteroassociation 
between ester and alkanol, together with the unfavorable packing of the molecules specially for the longer alkanols. On the other hand $V^{\mathrm{E}}$ for the system containing methanol is negative, in the case of methanol two different factors leads to the contraction in volume, on one hand his molecular size allows a better interstitial accommodation and on the other hand the above mentioned higher proton-donating ability of methanol.

With respect to vapour-liquid equilibrium positive deviations from ideal behavior resulting from unfavorable interactions between the mixed components lead to activity coefficients greater than unity and positive excess Gibbs functions. As we have previously discussed for $H^{\mathrm{E}}$ values, the unfavorable interactions in the mixture are predominant, so the excess Gibbs functions must be positive.

\section{UNIFAC predictions}

The modified-UNIFAC method has been used to predict the vapor-liquid equilibrium of the studied mixtures at the different experimental conditions, for the calculations we have employed the newest UNIFAC parameters available [80]. In Table 6 the coordinates of the UNIFAC-predicted azeotropes are shown while in Table 7 the deviations between the measured and predicted VLE data are given. The predicted azeotropic coordinates have been plotted in the corresponding Figs. The agreement between experimental and predicted azeotropic coordinates is quite good.

Figs. S1-S4 of the supplementary material present the comparison between the experimental and predicted isothermal VLE data at the temperatures 303.15 and $323.15 \mathrm{~K}$, or predicted isobaric VLE data at the pressures 40.000 and $101.325 \mathrm{kPa}$, for the ethyl isobutyrate + n-alkanol systems. 
According to Table 7 and Figs. S1-S4, the VLE data predicted by the UNIFAC model show good agreement with the experimental VLE data, being the overall average deviations $\Delta p=0.25 \mathrm{kPa}$ and $\Delta y=0.0141$ for isothermal conditions and $\Delta T=0.32 \mathrm{~K}$ and $\Delta y=0.0057$ for isobaric ones. It is clear that the predictions at $T=303.15 \mathrm{~K}$ or $p=101.325 \mathrm{kPa}$ are slightly better than at $T=323.15 \mathrm{~K}$ or $p=40.000 \mathrm{kPa}$. Finally, regarding the comparison of VLE predictions among the studied systems, the worst predictions correspond to the system ethyl isobutyrate + methanol, especially at isobaric conditions.

\section{Conclusions}

This work reported experimental density data for binary mixtures containing ethyl isobutyrate with C1-C4 n-alkanols at $\mathrm{p}=0.1 \mathrm{MPa}$, and at 303.15 and $323.15 \mathrm{~K}$. From experimental data, excess molar volumes and excess molar enthalpies have been determined and correlated using Redlich-Kister polynomial expansions. Both the isothermal vapor-liquid equilibria at two temperatures (303.15 and 323.15) $\mathrm{K}$ and isobaric vapor-liquid equilibria at two pressures (40.000 and 101.325) kPa have been determined over the whole composition range and azeotropes were observed. The VLE data were found to be thermodynamically consistent. The activity coefficients along with excess Gibbs and reduced excess Gibbs functions were obtained and correlated with composition using the Wilson equation. Positive deviations from ideality were obtained both for these excess Gibbs function and reduced excess Gibbs functions. The experimental results have been used to check the accuracy of modified UNIFAC predictions: the predictions are adequate except for the system containing 1-propanol under isothermal conditions, at $\mathrm{T}=323.15 \mathrm{~K}$. 


\section{Acknowledgements}

Authors acknowledge the financial support from Gobierno de Aragón (grant E31_17R) Fondo de Desarrollo Regional “Construyendo Europa desde Aragón” and the Ministry of superior education and scientific research of Tunisia. 


\section{References}

[1] R. Ciriminna, M. Pagliaro, Green chemistry in the fine chemicals and pharmaceutical industries, Org. Process Res. Dev. 17 (2013) 1479-1484.

[2] P. Singh, D. K. Saxena, S. N. Naik, Synthesis of food flavors by enzymatic esterification process, Int. J. Sci. Res. 3 (2014) 2113-2116.

[3] A. G. Almeida, A. C. De Meneses, P. H. H. De Araújo, D. De Oliveira, A review on enzymatic synthesis of aromatic esters used as flavor ingredients for food, cosmetics and pharmaceuticals industries, Trends Food Sci. Technol. 69 (2017) 95-105.

[4] D. P.C. De Barros, A. M. Azevedo, J. M.S. Cabral, L. P. Fonseca, Optimization of flavor esters synthesis by fusarium solani pisi cutinase, J. Food Biochem. 36 (2012) 275-284.

[5] J. L. Puech, F. Feuillat, J. R. Mosedale, The tannins of oak heartwood: Structure, properties, and their influence on wine Flavor, Am. J. Enol. Vitic. 50 (1999) 469-478.

[6] J. L. Epstein, M. Castaldi, G. Patel, P. Telidecki, K. Karakkatt, Using flavor chemistry to design and synthesize artificial scents and flavors, J. Chem. Educ. 92 (2015) 954-957.

[7] D. M. Birney, S. D. Starnes, Parallel combinatorial esterification: A simple experiment for use in the second-semester organic chemistry laboratory, J. Chem. Educ. 76 (1999) $1560-1561$.

[8] D. C. Bromfield-Lee, M. T. Oliver-Hoyo, An esterification kinetics experiment that relies on the sense of smell, J. Chem. Educ. 86 (2009) 82-84.

[9] T. Thomas-Danguin, C. Sinding, S. Romagny, F. El Mountassir, B. Atanasova, E. Le Berre, A. M. Le Bon, G. Coureaud, The perception of odor objects in everyday life: a review on the processing of odor mixtures, Front Psychol. 5 (2014) 504.

[10] P. L. H. Mcsweeney, M. J. Sousa, Biochemical pathways for the production of flavor compounds in cheeses during ripening: A review, Lait 80 (2000) 293-324. 
[11] J. Gmehling, J. Li, M. Schiller, A Modified UNIFAC model. 2. Present parameter matrix and results for different thermodynamic properties, Ind. Eng. Chem. Res. 32 (1993) 178-193.

[12] N. B. Mahdoui, M. Artal, M. Hichri, C. Lafuente, Volumetric behavior and vaporliquid equilibrium of dimethyl disulfide plus n-alkanol binary mixtures, J. Solution Chem. 48 (2019) 1-14.

[13] P. Monk, I. Wadsö, A flow micro reaction calorimeter, Acta Chem. Scand. 22 (1968) 1842-1852.

[14] C. Lafuente, H. Artigas, M.C. López, F.M. Royo, J.S. Urieta, Excess molar enthalpies for isomeric chlorobutanes with isomeric butanols, Phys. Chem. Liq. 39 (2001) 665673.

[15] K. N. Marsh, Recommended Reference Materials for the Realization of Physicochemical Properties, I.U.P.A.C., Blackwell Scientific Publications, Oxford, 1987.

[16] H. Artigas, C. Lafuente, M. C. López, F. M. Royo, J. S. Urieta, Isobaric vapor-liquid equilibria for binary mixtures of 1-chlorobutane with isomeric butanols at 40.0 and 101.3 kPa J. Chem. Eng. Data 39 (1994) 729-732.

[17] D. R. Stull, Vapor pressure of pure substances. Organic and inorganic compounds, Ind. Eng. Chem. 39 (1947) 517-540.

[18] W. H. Perkin, On the magnetic rotary polarisation of compounds in relation to their chemical consitution; with observations on the preparation and relative densities of the bodies examined, J. Chem. Soc. 45 (1884) 421-580.

[19] C. R. Hauser, W. B. Renfrow, Certain condensations brought about by bases. I. The condensation of ethyl isobutyrate to ethyl isobutyryl-isobutyrate, J. Am. Chem. Soc. 59 (1937) 1823-1826. 
[20] M. F. Ansell, W. J. Hickinbottom, P. G. Holton, The synthesis and reactions of branched-chain hydrocarbons: Part VI. The free- radical dimerisation of some esters and ketones, J. Chem. Soc. 0 (1955) 349-351.

[21] M. Zafarani-Moattar, H. Shekaari, Volumetric and speed of sound of ionic liquid, 1butyl-3-methylimidazolium hexafluorophosphate with acetonitrile and methanol at $\mathrm{T}=$ (298.15 to 318.15) K, J. Chem. Eng. Data 50 (2005) 1694-1699.

[22] A. Valtz, C. Coquelet, D. Richon, Volumetric properties of the monoethanolaminemethanol mixture at atmospheric pressure from 283.15 to $353.15 \mathrm{~K}$, Thermochim. Acta, 428 (2005) 185-191.

[23] X. Yang, Y. Fang, A volumetric and viscosity study for the binary mixtures of ammonium-based asymmetrical gemini ionic liquids with alcoholsat $\mathrm{T}=293.15-333.15$ K, J. Chem. Eng. Data 64 (2019) 722-735.

[24] K. Machanová, J. Troncoso, J. Jacquemin, M, Bendova, Excess molar volumes and excess molar enthalpies in binary systems N-alkyl-triethylammonium bis(trifluoromethylsulfonyl)imide plus methanol, Fluid Phase Equilib. 363 (2014) 156166.

[25] D. Ambrose, C. H. S. Sprake, Thermodynamic properties of organic oxygen compounds XXV. Vapour pressures and normal boiling temperatures of aliphatic alcohols, J. Chem. Thermodyn. 2 (1970) 631-645.

[26] X. Esteve, S. K. Chaudhari, A. Coronas, Vapor-liquid equilibria for methanol plus tetraethylene glycol dimethyl ether, J. Chem. Eng. Data 40 (1995) 1252-1256.

[27] R. Garriga, F. Sánchez, P. Perez, M. Gracia, Vapour pressures at eight temperatures between $278.15 \mathrm{~K}$ and $323.15 \mathrm{~K}$ and excess molar enthalpies and volumes at $\mathrm{T}=298.15$ K of (n-propylether plus methanol), J. Chem. Thermodyn. 29 (1997) 649-659. 
[28] R. S. Hansen, R. D. Hansen, The adsorption of hydrocarbons from methanol and ethanol solutions by non-porous carbons, J. Phys. Chem. 59 (1955) 496-498.

[29] M. M. Dribika, I. G. Rashed, M. W. Biddulph, Vapor-liquid equilibria in the ternary system methyl alcohol-ethyl alcohol-isopropyl alcohol at atmospheric pressure. J. Chem. Eng. Data 30 (1985) 146-149.

[30] Z. Li, Q. Li, R. Qiao, K. Zhang, X. Song, C. Li, H. Tang, Y. Liu, Isobaric vapor-liquid equilibrium for methanol plus methyl ethyl ketone plus bis(trifluoromethylsulfonyl)imide-based ionic liquids at $101.3 \mathrm{kPa}$. Fluid Phase Equilib. 427 (2016) 90-96.

[31] P. S. Nikam, L. N. Shirsat, M. Hasan, Density and viscosity studies of binary mixtures of acetonitrile with methanol, ethanol, propan-1-ol, propan-2-ol, butan-1-ol, 2methylpropan-1-ol, and 2- methylpropan-2-ol at (298.15, 303.15, 308.15, and 313.15) K, J. Chem. Eng. Data 43 (1998) 732-737.

[32] H. Djojoputro, S. Ismadji, Density and viscosity of binary mixtures of ethyl-2methylbutyrate and ethyl hexanoate with methanol, ethanol, and 1-propanol at (293.15, 303.15, and 313.15) K, J. Chem. Eng. Data 50 (2005) 1343-1347.

[33] B. H. Park, Volumetric properties of binary mixtures of 1-butyl- 3-methylimidazolium halides with water, methanol or ethanol at 293.15 to 318.15 K, Korean J. Chem. Eng. 33 (2016) 2191-2204.

[34] D. Pečar, V. Doleček, Volumetric properties of ethanol-water mixtures under high temperatures and pressures, Fluid Phase Equilibr. 230 (2005) 36-44.

[35] Q. Zhou, Y. T. Song, Y. H. Yu, H. Y. He, S. J. Zhang, Density and excess molar volume for binary mixtures of naphthenic acid ionic liquids and ethanol, J. Chem. Eng. Data 55 (2010) 1105-1108. 
[36] A. García-Abuín, D. Gómez-Díaz, M.D. La Rubia, J.M. Navaza, Density, speed of sound, viscosity, refractive index, and excess volume of $\mathrm{N}$-methyl-2- pyrrolidone + ethanol (or water or ethanolamine) from $\mathrm{T}=(293.15$ to 323.15$) \mathrm{K}$, J. Chem. Eng. Data 56 (2011) 645-651.

[37] C. B. Kretschmer, R. Wiebe, Liquid-vapor equilibrium of ethanol-toluene solutions, J. Am. Chem. Soc. 71 (1949) 1793-1797,

[38] D. Ambrose, N.B. Ghiassee, Vapor-pressures and critical temperatures and critical pressures of some alkanoic acids C-1 to C-10, J. Chem. Thermodyn. 19 (1987) 505-519.

[39] R. Garriga, S. Martínez, P. Pérez, M. Gracia, Vapour pressures at 10 different temperatures between 278.15 and $323.15 \mathrm{~K}$ for binary mixturesof 1-bromobutane with ethanol or 1-hexanol, J. Chem. Thermodyn. 207 (2003) 97-109.

[40] C. González, H.C. van Ness, Excess thermodynamic functions for ternary systems. 8. Total pressure data and GE for ethanol/chloroform/1,4-dioxane at $50^{\circ} \mathrm{C}$, J. Chem. Eng. Data 28 (1983) 407-409.

[41] M. Kato, H. Konishi, M. Hirata, New apparatus for isobaric dew and bubble point method methanol + water, ethyl acetate + ethanol, water + 1-butanol, and ethyl acetate + water systems, J. Chem. Eng. Data 15 (1970) 435-439.

[42] M. Kato, H. Tanaka, Vapor-liquid equilibrium determination with a flow-type ebulliometer for six binary systems made of alcohol and amine. J. Chem. Eng. Data 34 (1989) 203-206.

[43] C. Pienaar, C. E. Schwarz, J. H. Knoetze, A. J. Burger, Vapor-liquid-liquid equilibria measurements for the dehydration of ethanol, isopropanol, and n-propanol via azeotropic distillation using DIPE and isooctane as entrainers. J. Chem. Eng. Data 58 (2013) 537-550. 
[44] C. N.Rao, L. Venkataramana, C. L. Prabhavathi, K. Sivakumar, R. L. Gardas, Excess thermodynamic and spectroscopic study ofternary mixtures containing Nmethylcyclohexylamine, bromobenzene, and 1-alkanols at $303.15 \mathrm{~K}$, J. Therm. Anal. Calorim. 123 (2016) 881-890.

[45] G. A.Iglesias-Silva, A. Guzmán-López, G. Pérez-Durán, M. Ramos-Estrada, Densities and viscosities for binary mixtures of n-undecane + 1-propanol, + 1-butanol, + 1pentanol, and + 1-hexanol from283.15 to $363.15 \mathrm{~K}$ at $0.1 \mathrm{MPa}$, J. Chem. Eng. Data 31 (2016) 2682-2699.

[46] A.M. Awwad, H.M. Alsyouri, M.A. Abu-Daabes, K.A. Jbara, Densities and volumetric properties of (N-(2-hydroxyethyl)morpholine + ethanol, + 1-propanol,+ 2-propanol, + 1-butanol, and + 2-butanol) at (293.15, 298.15, 303.15, 313.15, and 323.15) K, J. Chem. Thermodyn. 40 (2008) 592-598.

[47] F. Kermanpour, T.S. Ettefagh, H. Iloukhani, Measurement and calculation the excess molar properties of binary mixtures containing isobutanol, 1-amino-2- propanol, and 1propanol at temperatures of (293.15 to 333.15) K, J. Solution Chem. 46 (2017) 446-460.

[48] H. R. Kemme, S. I. Kreps, Vapor pressure of primary n-alkyl chlorides and alcohols, J. Chem. Eng. Data 14 (1969) 98-102.

[49] J. Safarov, S. P. Verevkin, E. Bich, A. Heintz, Vapor pressures and activity coefficients of n-alcoholsand benzene in binary mixtures with 1-methyl-3-butylimidazolium octyl sulfate and 1-methyl-3-octylimidazolium tetrafluoroborate, J. Chem. Eng. Data 51 (2006) 518-525.

[50] K. Wysoczanska, N. Calvar, E. A. Macedo, (Vapour + liquid) equilibria of alcohol + 1methyl-1-propylpiperidinium triflate ionic liquid: VPO measurements and modelling. J. Chem. Thermodyn. 97 (2016) 183-190. 
[51] I. Brown, W. Fock, F. Smith, The thermodynamic properties of solutions of normal and branched alcohols in benzene and n-hexane, J. Chem. Thermodyn. 1 (1969) 273-291.

[52] T. Hiaki, K. Takahashi, T. Tsuji, M. Hongo, K. Kojima, Vapor-liquid equilibria of ethanol + 2,2,4-trimethylpentane at 333.15 K and 1-propanol + 2,2,4-trimethylpentane at 343.15 K, J. Chem. Eng. Data 39 (1994) 605-607.

[53] V. K. Reddy, K. Rambabu, T. Devarajulu, A. Krishnaiah, Volume of mixing, speed of sound, and viscosity of methyl cellosolve with aliphatic alcohols at $308.15 \mathrm{~K}$, J. Chem. Eng. Data 40 (1995) 124-127.

[54] V. Mutalik, L.S. Manjeshwar, M. Sairam, T.M. Aminabhavi, Thermodynamic interactions in binary mixtures of anisole with ethanol, propan-1-ol, propan-2-ol, butan1-ol, pentan-1-ol, and 3-methylbutan-1-ol at $=(298.15,303.15$, and 308.15) $\mathrm{K}$, J. Chem. Thermodyn. 38 (2006) 1620-1628.

[55] M.G. Bravo-Sánchez, G.A. Iglesias-Silva, A. Estrada-Baltazar, K.R. Hall, Densitiesand viscosities of binary mixtures of n-butanol with 2-butanol, isobutanol, andtert-butanol from (303.15 to 343.15) K, J. Chem. Eng. Data 55 (2010) 2310-2315.

[56] Z. L. Grygorian, E. A. Kazoyan, Sh.A.Markaryan, Thermodynamics of liquid-vapour phase equilibrium in dimethyl sulfoxide - alkanol systems in the range of 293.15 323.15 K. Russ. J. Phys. Chem. 89 (2015) 1790-1794.

[57] A. Krishnaiah, N. V. Choudary, Activity coefficients and excess Gibbs free energies of 1,2-dichlor- ethane with isomeric butanols, J. Chem. Eng. Data 32 (1987) 196-198.

[58] J. L. Cabezas, S. Beltran, J. Coca,Isobaric vapor-liquidequilibrium data for the binary systems 1,2- dimethoxyethane +alcohols. J. Chem. Eng. Data 36 (1991) 184-188.

[59] E. Gonzalez, J. Ortega, Densities and isobaric vapor-liquidequilibria for the mixtures formed by four butyl esters and 1-butanol, J. Chem. Eng. Data 41 (1996) 53-58. 
[60] W. H. Perkin, On the magnetic rotary polarisation of compounds in relation to their chemical consitution; with observations on the preparation and relative densities of the bodies examined, J. Chem. Soc. 45 (1884) 421-580.

[61] T. W. Richards, J. H. Mathews, The relation between compressibility, surface tension, and other properties of material, J. Am. Chem. Soc. 30 (1908) 8-13.

[62] A. I. Vogel, Physical properties and chemical constitution. XIII. Aliphatic carboxylic esters, J. Chem. Soc. (1948) 624-644.

[63] F. Comelli, R. Francesconi, S. Ottani, Excess molar enthalpies of binary mixtures containing propylene carbonate +23 alkanoates at 298.15 K, J. Chem. Eng. Data, 43 (1998) 333-336.

[64] R. Privat, J.-N. Jaubert, Discussion around the paradigm of ideal mixtures with emphasison the definition of the property changes on mixing, Chem. Eng. Sci. 83 (2012) 319-333.

[65] O. Redlich, A.T. Kister, Algebraic representation of thermodynamic properties and the classification of solutions, Ind. Eng. Chem. 40 (1948) 341-345.

[66] J. M. Smith, H. C. Van Ness, M. M. Abbott, Introduction to Chemical Engineering Thermodynamics, $5^{\text {th }}$ Ed. McGraw-Hill Education, 1996.

[67] C. Tsonopoulos, Empirical correlation of second virial coefficients, AIChE J. 20 (1974) 263-272.

[68] C. Tsonopoulos, J. L. Heidman, From the virial to the cubic equation of state, Fluid Phase Equilib. 57 (1990) 261-276.

[69] H. G. Rackett, Equation of state for saturated liquids, J. Chem. Eng. Data 15 (1970) 514-517. 
[70] J. A. Riddick, W. B. Bunger, T. K. Sakano, Organic Solvents: Physical Properties and Methods of Purification, 4th ed.; Techniques of Chemistry, Vol. II; Wiley-Interscience, New York, 1986.

[71] G. M. Wilson, Vapor-liquid equilibrium. 11. New expression for excess free energy of mixing, J. Am. Chem. Soc. 86 (1964) 127-130.

[72] N. Silverman, D. Tassios, Prediction of multicomponent vapor liquid equilibrium with the Wilson equation - Effect of the minimization function and of the quality of binary data. Ind. Eng. Chem. Proc. Des. Dev. 23 (1984) 586-589.

[73] S. Villa, R. Garriga, P. Pérez, M. Gracia, J. A. González, I. G. de la Fuente, J. C. Cobos, Thermodynamics of mixtures with strongly negative deviations from Raoult's law Part 9. Vapor-liquid equilibria for the system 1-propanol plus di-n-propylamine at six temperatures between 293.15 and 318.15 K, Fluid Phase Equilib. 231 (2005) 211-220.

[74] H. C. van Ness, S. M. Byer, R. E. Gibbs, Vapor-liquid equilibria. I. Appraisal of data reduction methods, AIChE J. 19 (1973) 238-244.

[75] A. Fredenslund, J. Gmehling, P. Rasmussen, Vapor-Liquid Equilibria Using UNIFAC, Elsevier, Amsterdam, 1977.

[76] P. Sivagurunathan, K. Dharmalingam, K. Ramachandran, Molecular interaction studies of acrylic esters with 1-alcohols, Spectrochim. Acta A, 64 (2006) 127-129.

[77] J. Ortega, C. González, J. Pena, S. Galván, Thermodynamic study on binary mixtures of propyl ethanoate and an alkan-1-ol (C-2-C-4). Isobaric vapor-liquid equilibria and excess properties, Fluid Phase Equilibr. 170 (2000) 87-111.

[78] Y. Marcus, Introduction to Liquid State Chemistry, Wiley Interscience, NewYork, 1977.

[79] R. Mecke, Infra-red spectra of hydroxylic compounds, Discuss. Faraday Soc. 9 (1950) 161-177. 
[80] J. W. Kang, V. Diky, M. Frenkel, New modified UNIFAC parameters using critically evaluated phase equilibrium data, Fluid Phase Equilib. 388 (2015) 128-141. 
Table 1

Sample table.

\begin{tabular}{ccccccc}
\hline Compound & CAS number & Source & $\begin{array}{c}\text { Purity } \\
\text { (mass fraction) }\end{array}$ & $\begin{array}{c}\text { Analysis } \\
\text { method }\end{array}$ & $\begin{array}{c}\text { Water } \\
\text { content / ppm }\end{array}$ & $\begin{array}{c}\text { Water content } \\
\text { method }\end{array}$ \\
\hline Ethyl isobutyrate & $97-62-1$ & Aldrich & 0.998 & GC & 250 & KF \\
Methanol & $67-56-1$ & Sigma-Aldrich & 0.998 & GC & 295 & KF \\
Ethanol & $64-17-5$ & Acros & 0.998 & GC & 280 & KF \\
1-Propanol & $71-23-8$ & Sigma-Aldrich & 0.998 & GC & 300 & KF \\
1-Butanol & $71-36-3$ & Sigma-Aldrich & 0.999 & GC & 275 & KF \\
\hline
\end{tabular}

${ }^{\mathrm{a}}$ As stated by the supplier 


\section{Table 2}

Density (at $p=0.1 \mathrm{MPa}$ ), $\rho$, and vapour pressures, $p^{\circ}$, at working temperatures, and normal boiling point, $T_{\mathrm{b}}$, of the pure compounds: experimental and literature values. ${ }^{a}$

\begin{tabular}{|c|c|c|c|c|c|c|}
\hline \multirow{2}{*}{$T / \mathrm{K}$} & \multicolumn{2}{|r|}{$\rho / \mathrm{g} \cdot \mathrm{cm}^{-3}$} & \multicolumn{2}{|r|}{$p^{\mathrm{o}} / \mathrm{kPa}$} & \multicolumn{2}{|r|}{$T_{\mathrm{b}} / \mathrm{K}$} \\
\hline & Exptl. & Lit. & Exptl. & Lit. & Exptl. & Lit. \\
\hline \multicolumn{7}{|c|}{ Ethyl isobutyrate } \\
\hline 303.15 & 0.85792 & & 4.340 & $4.400[17]$ & 383.59 & $383.45[18] 383.65$ [19] 383.4 [20] \\
\hline 323.15 & 0.83605 & & 11.660 & $11.368[17]$ & & \\
\hline \multicolumn{7}{|c|}{ Methanol } \\
\hline 303.15 & 0.78181 & $0.781808[21] 0.78186[22] 0.78190[23]$ & 21.880 & 21.86 [25] 21.90 [26] 21.904 [27] & 337.96 & 337.96 [28] 337.92 [29] 337.9 [30] \\
\hline 323.15 & 0.76261 & $0.76267[22] 0.76270$ [23] 0.76271 [24] & 55.735 & 55.539 [25] 55.60 [26] 55.566 [27] & & \\
\hline \multicolumn{7}{|c|}{ Ethanol } \\
\hline 303.15 & 0.78078 & $0.78075[31] 0.78073[32] 0.78078[33]$ & 10.465 & 10.470 [37] 10.462 [38] 10.475 [39] & 351.48 & 351.53 [41] 351.49 [42] 351.47 [43] \\
\hline 323.15 & 0.76361 & 0.7637 [34] 0.763643 [35] 0.76329 [36] & 29.545 & 29.439 [37] 29.494 [38] 29.510 [40] & & \\
\hline \multicolumn{7}{|c|}{ 1-Propanol } \\
\hline 303.15 & 0.79553 & $0.79548[31] 0.79566$ [44] 0.79558 [45] & 3.800 & 3.851 [39] 3.860 [48] 3.826 [49] & 370.21 & 370.23 [51] 370.26 [52] 370.20 [53] \\
\hline 323.15 & 0.77909 & 0.77911 [45] 0.77897 [46] 0.77906 [47] & 12.185 & 12.148 [39] 12.090 [48] 12.10 [50] & & \\
\hline \multicolumn{7}{|c|}{ 1-Butanol } \\
\hline 303.15 & 0.80191 & $0.80201[31] 0.80205[44] 0.80194$ [45] & 1.225 & $1.280[39] 1.271[48] 1.200[56]$ & 390.74 & 390.75 [57] 390.75 [58] 390.77[59] \\
\hline 323.15 & 0.78662 & 0.78630 [45] 0.78667 [54] 0.78645 [55] & 4.505 & $4.556[39] 4.623[48] 4.48[50]$ & & \\
\hline
\end{tabular}

${ }^{a}$ Standard uncertainties $u$ are $u(T)=0.005 \mathrm{~K}, u(p)=2.5 \mathrm{kPa}$ for density measurements, and $u(T)=0.1 \mathrm{~K}, u(p)=0.1 \mathrm{kPa}$ for vapour-liquid equilibrium measurements, and the combined expanded uncertainties $U_{\mathrm{c}}$ are $U_{\mathrm{c}}(\rho)=2 \cdot 10^{-4} \mathrm{~g} \cdot \mathrm{cm}^{-3}$ with 0.95 level of confidence $(\mathrm{k}=2)$. 
Table 3

Parameters of the Redlich-Kister equation, $A_{\mathrm{i}}$, and standard deviations, $\sigma\left(Y^{\mathrm{E}}\right)$.

\begin{tabular}{|c|c|c|c|c|c|c|}
\hline Function & $T / \mathrm{K}$ & $A_{0}$ & $A_{1}$ & $A_{2}$ & $A_{3}$ & $\sigma\left(Y^{\mathrm{E}}\right)$ \\
\hline \multicolumn{7}{|c|}{ Etyhl isobutyrate (1) + methanol (2) } \\
\hline \multirow{2}{*}{$V^{\mathrm{E}} /\left(\mathrm{cm}^{3} \cdot \mathrm{mol}^{-1}\right)$} & 303.15 & -0.5111 & 0.0233 & -0.0503 & & 0.0014 \\
\hline & 323.15 & -0.3602 & 0.0066 & -0.0433 & 0.0524 & 0.0009 \\
\hline \multirow{2}{*}{$H^{\mathrm{E}} /\left(\mathrm{J} \cdot \mathrm{mol}^{-1}\right)$} & 303.15 & 2723 & 1156 & 871 & & 3 \\
\hline & 323.15 & 4482 & 1556 & 473 & -512 & 5 \\
\hline \multicolumn{7}{|c|}{ Etyhl isobutyrate (1) + ethanol (2) } \\
\hline \multirow{2}{*}{$V^{\mathrm{E}} /\left(\mathrm{cm}^{3} \cdot \mathrm{mol}^{-1}\right)$} & 303.15 & 0.2942 & -0.0187 & -0.166 & 0.0684 & 0.0008 \\
\hline & 323.15 & 0.5316 & -0.002 & -0.1562 & 0.2114 & 0.0011 \\
\hline \multirow{2}{*}{$H^{\mathrm{E}} /\left(\mathrm{J} \cdot \mathrm{mol}^{-1}\right)$} & 303.15 & 4713 & 1172 & 915 & & 3 \\
\hline & 323.15 & 5516 & 1161 & 882 & & 5 \\
\hline \multicolumn{7}{|c|}{ Etyhl isobutyrate (1) + 1-propanol (2) } \\
\hline \multirow{2}{*}{$V^{\mathrm{E}} /\left(\mathrm{cm}^{3} \cdot \mathrm{mol}^{-1}\right)$} & 303.15 & 0.3728 & -0.0296 & -0.1468 & 0.1599 & 0.0009 \\
\hline & 323.15 & 0.5859 & -0.0164 & -0.0568 & 0.2993 & 0.0012 \\
\hline \multirow{2}{*}{$H^{\mathrm{E}} /\left(\mathrm{J} \cdot \mathrm{mol}^{-1}\right)$} & 303.15 & 5286 & 1189 & 682 & -270 & 4 \\
\hline & 323.15 & 6095 & 1072 & 636 & -145 & 3 \\
\hline \multicolumn{7}{|c|}{ Etyhl isobutyrate (1) + 1-butanol (2) } \\
\hline \multirow{2}{*}{$V^{\mathrm{E}} /\left(\mathrm{cm}^{3} \cdot \mathrm{mol}^{-1}\right)$} & 303.15 & 0.4727 & -0.0217 & -0.1209 & 0.1702 & 0.0012 \\
\hline & 323.15 & 0.6530 & -0.0236 & 0.0175 & 0.2928 & 0.0016 \\
\hline \multirow{2}{*}{$H^{\mathrm{E}} /\left(\mathrm{J} \cdot \mathrm{mol}^{-1}\right)$} & 303.15 & 5614 & 1176 & 1069 & -132 & 4 \\
\hline & 323.15 & 6222 & 1030 & 940 & 82 & 3 \\
\hline
\end{tabular}




\section{Table 4}

Parameters of the Wilson equation, $\lambda_{\mathrm{ij}}-\lambda_{\mathrm{ii}}$, average deviation in pressure, $\Delta p$, or average deviation in temperature, $\Delta T$, and average deviation in vapour phase composition, $\Delta y$.

\begin{tabular}{|c|c|c|c|c|c|}
\hline System & $T / \mathrm{K}$ & $\begin{array}{l}\lambda_{12-} \lambda_{11} / \\
\left(\mathrm{J} \mathrm{mol}^{-1}\right)\end{array}$ & $\begin{array}{l}\lambda_{21}-\lambda_{22} / \\
\left(\mathrm{J} \mathrm{mol}^{-1}\right)\end{array}$ & $\Delta p / \mathrm{kPa}$ & $\Delta y$ \\
\hline \multirow{2}{*}{ Ethyl isobutyrate (1) + methanol (2) } & 303.15 & -179.58 & 4425.06 & 0.024 & 0.0035 \\
\hline & 323.15 & -565.05 & 4891.93 & 0.026 & 0.0041 \\
\hline \multirow{2}{*}{ Ethyl isobutyrate (1) + ethanol (2) } & 303.15 & 726.70 & 3090.08 & 0.025 & 0.0039 \\
\hline & 323.15 & -29.75 & 3410.07 & 0.026 & 0.0034 \\
\hline \multirow{2}{*}{ Ethyl isobutyrate (1) + 1-propanol (2) } & 303.15 & 839.63 & 2236.45 & 0.023 & 0.0050 \\
\hline & 323.15 & 591.19 & 2213.69 & 0.015 & 0.0037 \\
\hline \multirow{3}{*}{ Ethyl isobutyrate (1) + 1-butanol (2) } & 303.15 & 470.37 & 2165.35 & 0.016 & 0.0035 \\
\hline & 323.15 & 87.49 & 2366.58 & 0.029 & 0.0039 \\
\hline & $p / \mathrm{kPa}$ & $\begin{array}{l}\lambda_{12-} \lambda_{11} / \\
\left(\mathrm{J} \mathrm{mol}^{-1}\right)\end{array}$ & $\begin{array}{l}\lambda_{21}-\lambda_{22} / \\
\left(\mathrm{J} \mathrm{mol}^{-1}\right)\end{array}$ & $\Delta T / \mathrm{K}$ & $\Delta y$ \\
\hline \multirow{2}{*}{ Ethyl isobutyrate (1) + methanol (2) } & 40.000 & -911.66 & 4815.21 & 0.26 & 0.0046 \\
\hline & 101.325 & -855.55 & 4910.41 & 0.08 & 0.0039 \\
\hline \multirow{2}{*}{ Ethyl isobutyrate (1) + ethanol (2) } & 40.000 & -829.96 & 3980.86 & 0.25 & 0.0043 \\
\hline & 101.325 & -782.32 & 3871.66 & 0.09 & 0.0031 \\
\hline \multirow{2}{*}{ Ethyl isobutyrate (1) + 1-propanol (2) } & 40.000 & -274.14 & 2594.57 & 0.28 & 0.0045 \\
\hline & 101.325 & -536.56 & 2720.92 & 0.09 & 0.0043 \\
\hline \multirow{2}{*}{ Ethyl isobutyrate (1) + 1-butanol (2) } & 40.000 & -1294.96 & 3422.54 & 0.31 & 0.0042 \\
\hline & 101.325 & -513.39 & 2290.45 & 0.10 & 0.0049 \\
\hline
\end{tabular}




\section{Table 5}

Thermodynamic consistency test: average deviations in pressure, $\Delta p$, and average deviations in vapour phase composition, $\Delta y$.

\begin{tabular}{cccc}
\hline System & $T / \mathrm{K}$ & $\Delta p / \mathrm{kPa}$ & $\Delta y$ \\
\hline Ethyl isobutyrate (1) + methanol (2) & 303.15 & 0.014 & 0.0035 \\
& 323.15 & 0.016 & 0.0042 \\
Ethyl isobutyrate (1) + ethanol (2) & 303.15 & 0.025 & 0.0035 \\
Ethyl isobutyrate (1) + 1-propanol (2) & 323.15 & 0.013 & 0.0035 \\
Ethyl isobutyrate (1) + 1-butanol (2) & 303.15 & 0.018 & 0.0061 \\
& 323.15 & 0.010 & 0.0041 \\
Ethyl isobutyrate (1) + methanol (2) & 303.15 & 0.016 & 0.0039 \\
& 323.15 & 0.016 & 0.0042 \\
\hline Ethyl isobutyrate (1) + ethanol (2) & $p / \mathrm{kPa}$ & $\Delta p / \mathrm{kPa}$ & $\Delta y$ \\
\hline Ethyl isobutyrate (1) + 1-propanol (2) & 40.000 & 0.46 & 0.0040 \\
& 101.325 & 0.23 & 0.0027 \\
Ethyl isobutyrate (1) + 1-butanol (2) & 40.000 & 0.43 & 0.0039 \\
& 101.325 & 0.31 & 0.0026 \\
& 40.000 & 0.47 & 0.0043 \\
\hline
\end{tabular}




\section{Table 6}

Azeotropic coordinates (temperature, $T_{\mathrm{az}}$, or pressure, $p_{\mathrm{az}}$, and composition, $x_{1, \mathrm{az}}$ ): experimental coordinates and UNIFAC predictions.

\begin{tabular}{|c|c|c|c|c|c|}
\hline \multirow{2}{*}{ System } & \multirow{2}{*}{$T / \mathrm{K}$} & \multicolumn{2}{|c|}{$p_{\text {az }} / \mathrm{kPa}$} & \multicolumn{2}{|c|}{$x_{1, \mathrm{az}}$} \\
\hline & & Exptl. & UNIFAC & Exptl. & UNIFAC \\
\hline \multirow{2}{*}{ Ethyl isobutyrate (1) + ethanol (2) } & 303.15 & 10.87 & 10.56 & 0.144 & 0.096 \\
\hline & 323.15 & 29.83 & 29.59 & 0.083 & 0.039 \\
\hline \multirow{4}{*}{ Ethyl isobutyrate (1) + 1-propanol (2) } & 303.15 & 5.23 & 5.26 & 0.538 & 0.623 \\
\hline & 323.15 & 14.90 & 14.91 & 0.446 & 0.523 \\
\hline & ( & \multicolumn{2}{|c|}{$T_{\mathrm{az}} / \mathrm{K}$} & \multicolumn{2}{|c|}{$x_{1, \mathrm{az}}$} \\
\hline & $p / \mathrm{kPd}$ & Exptl. & UNIFAC & Exptl. & UNIFAC \\
\hline \multirow{2}{*}{ Ethyl isobutyrate (1) + 1-propanol (2) } & 40.000 & 345.9 & 345.8 & 0.318 & 0.366 \\
\hline & 101.325 & 369.7 & 369.7 & 0.188 & 0.196 \\
\hline \multirow{2}{*}{ Ethyl isobutyrate (1) + 1-butanol (2) } & 40.000 & 354.7 & 354.7 & 0.906 & 0.899 \\
\hline & 101.325 & 382.5 & 382.6 & 0.773 & 0.794 \\
\hline
\end{tabular}




\section{Table 7}

UNIFAC predictions: average deviation in pressure, $\Delta p$, or in temperature, $\Delta T$, and in vapour phase composition, $\Delta y$.

\begin{tabular}{cccc}
\hline System & $T / \mathrm{K}$ & $\Delta p / \mathrm{kPa}$ & $\Delta y$ \\
\hline Ethyl isobutyrate (1) + methanol (2) & 303.15 & 0.26 & 0.0091 \\
& 323.15 & 0.47 & 0.0036 \\
Ethyl isobutyrate (1) + ethanol (2) & 303.15 & 0.30 & 0.0215 \\
Ethyl isobutyrate (1) + 1-propanol (2) & 323.15 & 0.43 & 0.0134 \\
& 303.15 & 0.11 & 0.0225 \\
Ethyl isobutyrate (1) + 1-butanol (2) & 323.15 & 0.24 & 0.0174 \\
& 303.15 & 0.08 & 0.0148 \\
Ethyl isobutyrate (1) + methanol (2) & 323.15 & 0.13 & 0.0108 \\
\hline Ethyl isobutyrate (1) + ethanol (2) & $p / \mathrm{kPa}$ & $\Delta T / \mathrm{K}$ & $\Delta y$ \\
\hline Ethyl isobutyrate (1) + 1-propanol (2) & 40.000 & 0.85 & 0.0094 \\
& 101.325 & 0.75 & 0.0067 \\
Ethyl isobutyrate (1) + 1-butanol (2) & 40.000 & 0.19 & 0.0058 \\
& 101.325 & 0.08 & 0.0032 \\
& 40.000 & 0.31 & 0.0100 \\
& 101.325 & 0.13 & 0.0050 \\
\hline
\end{tabular}




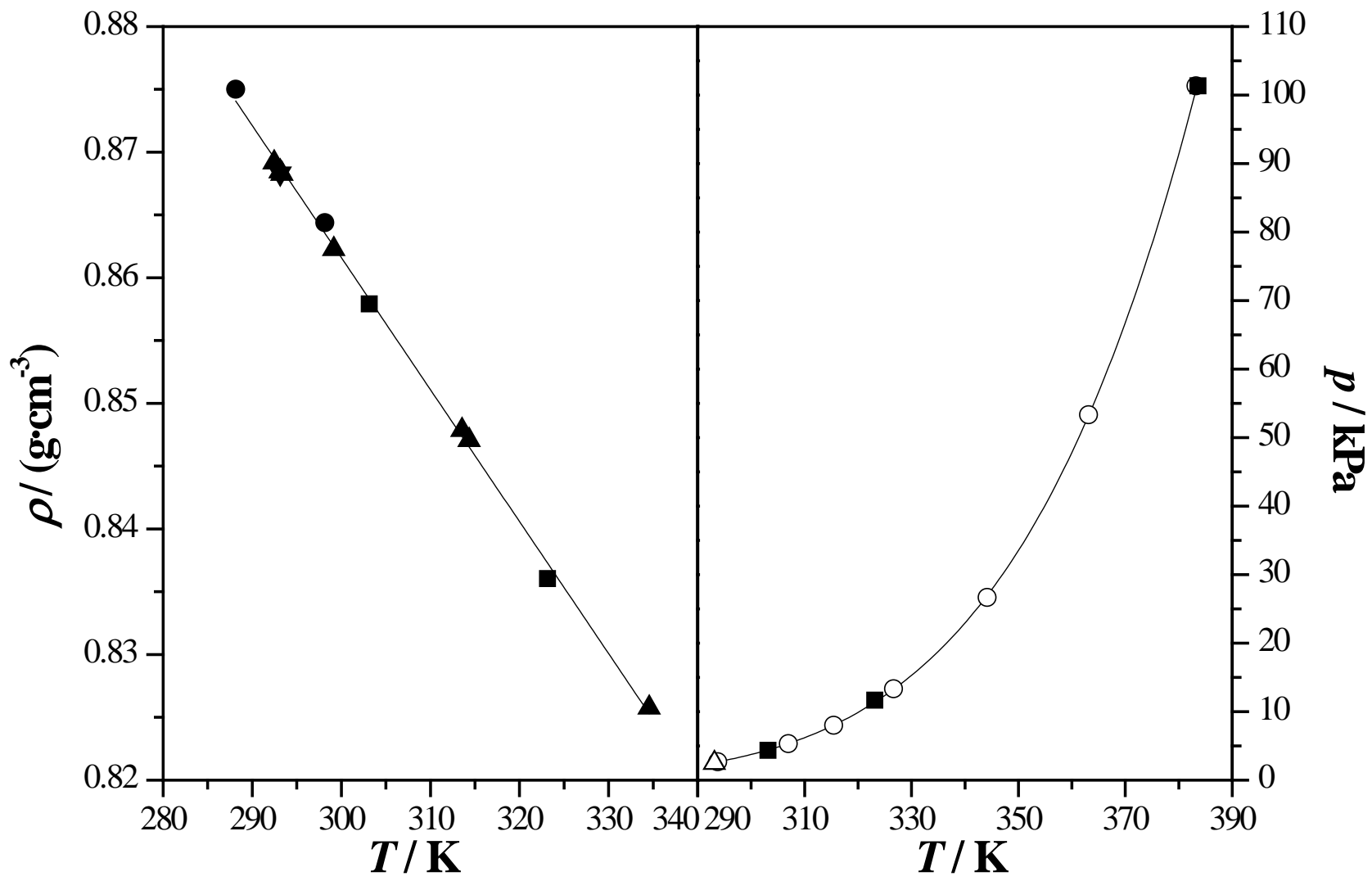

Fig. 1. Densities at $p=0.1 \mathrm{MPa}, \rho$, and vapour pressures, $p$, as a function of temperature, $T$,

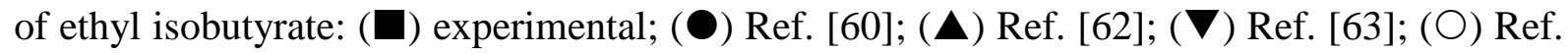
[17]; $(\triangle)$ Ref. [61]; $(-)$ correlated values. 


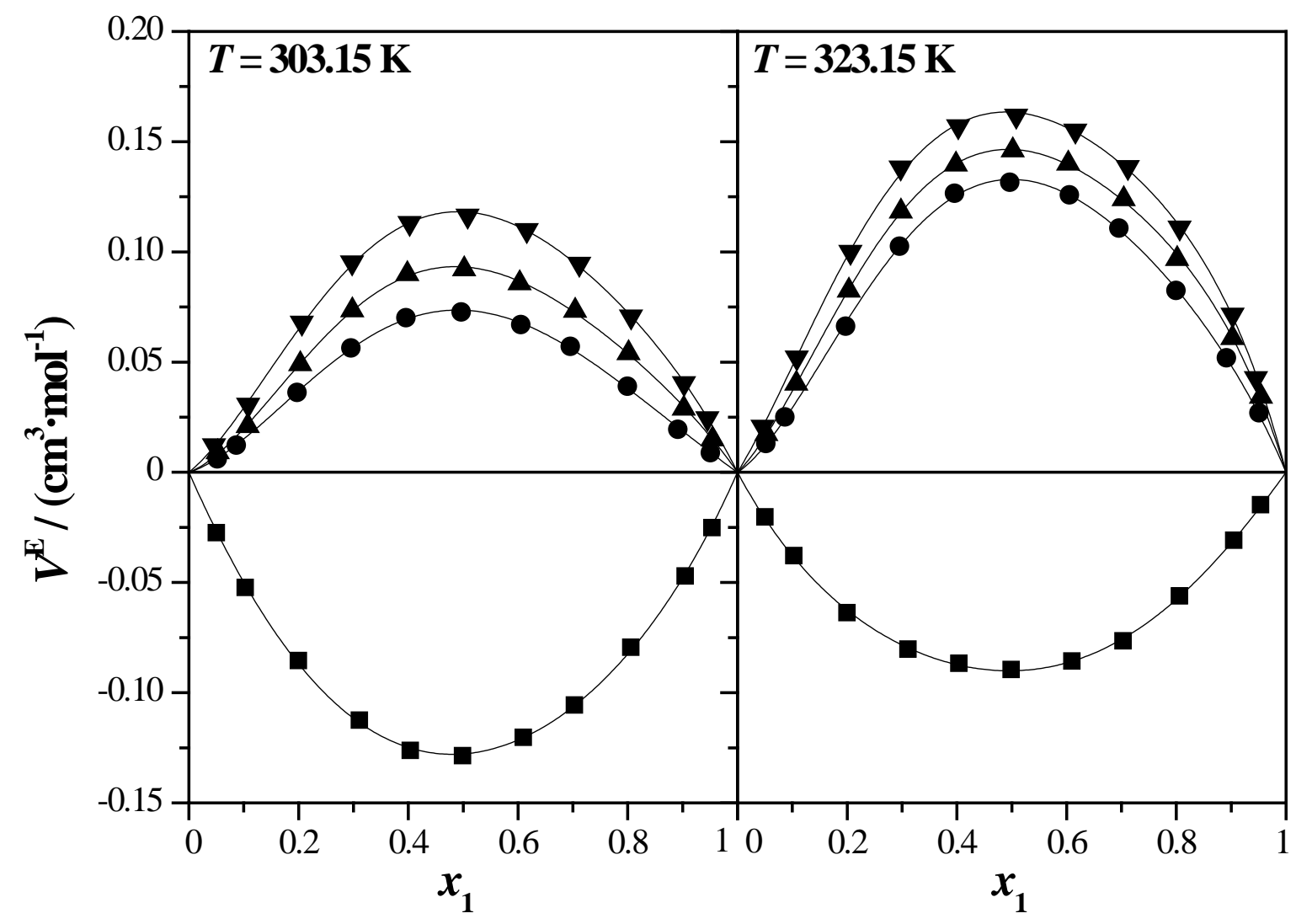

Fig. 2. Excess molar volumes, $V^{\mathrm{E}}$, as a function of the mole fraction, $x_{1}$, at $p=0.1 \mathrm{MPa}$ and at working temperatures for the binary mixtures ethyl isobutyrate (1) + alkanol (2): methanol; (O) ethanol; ( $\mathbf{\Delta})$ 1-propanol; $(\boldsymbol{\nabla})$ 1-butanol; (-) Redlich-Kister equation. 


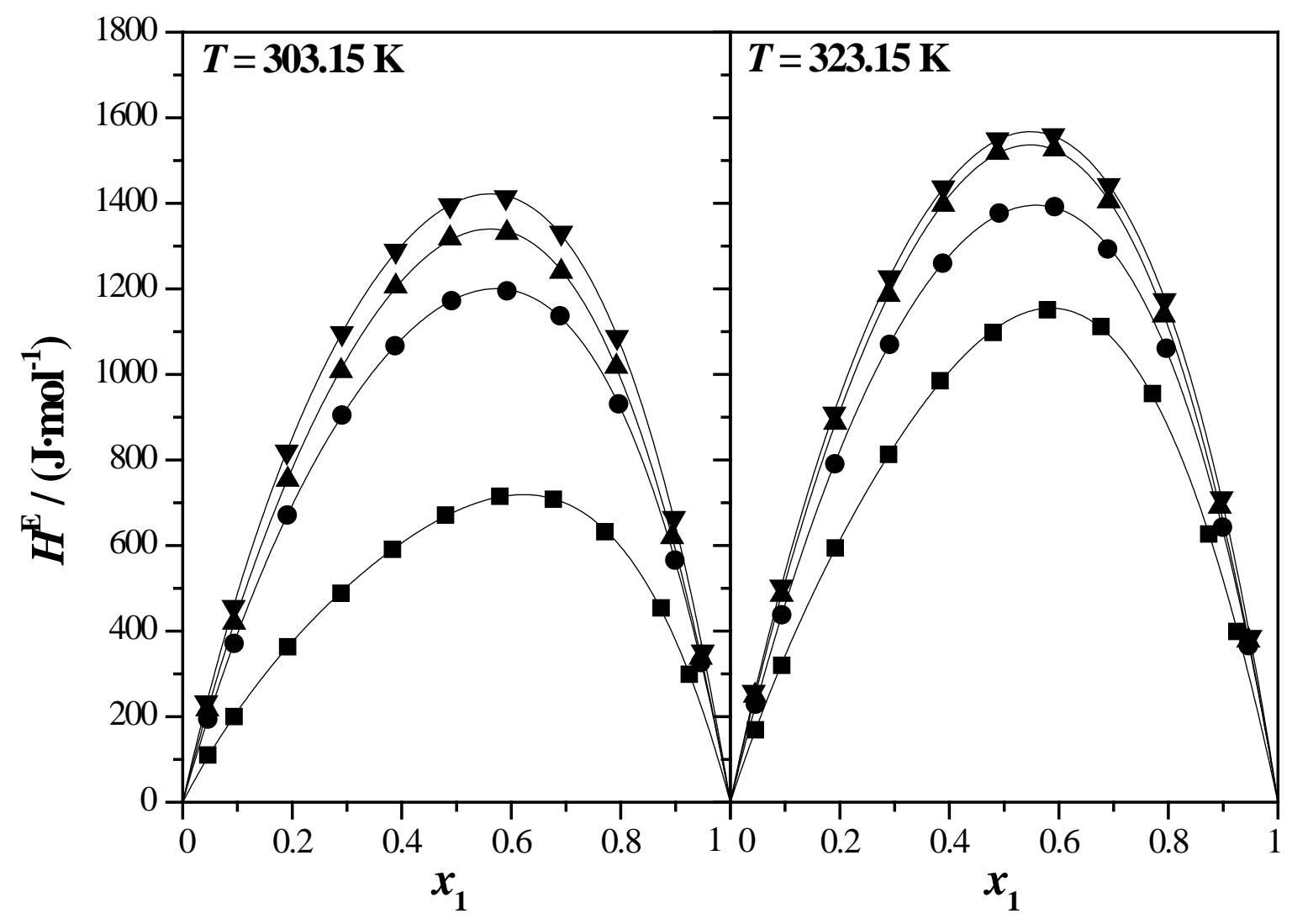

Fig. 3. Excess molar enthalpies, $H^{\mathrm{E}}$, as a function of the mole fraction, $x_{1}$, at $p=0.1 \mathrm{MPa}$ and at working temperatures for the binary mixtures ethyl isobutyrate (1) + alkanol (2): methanol; ( $(\boldsymbol{O})$ ethanol; $(\boldsymbol{\Delta})$ 1-propanol; $(\boldsymbol{\nabla})$ 1-butanol; (-) Redlich-Kister equation. 


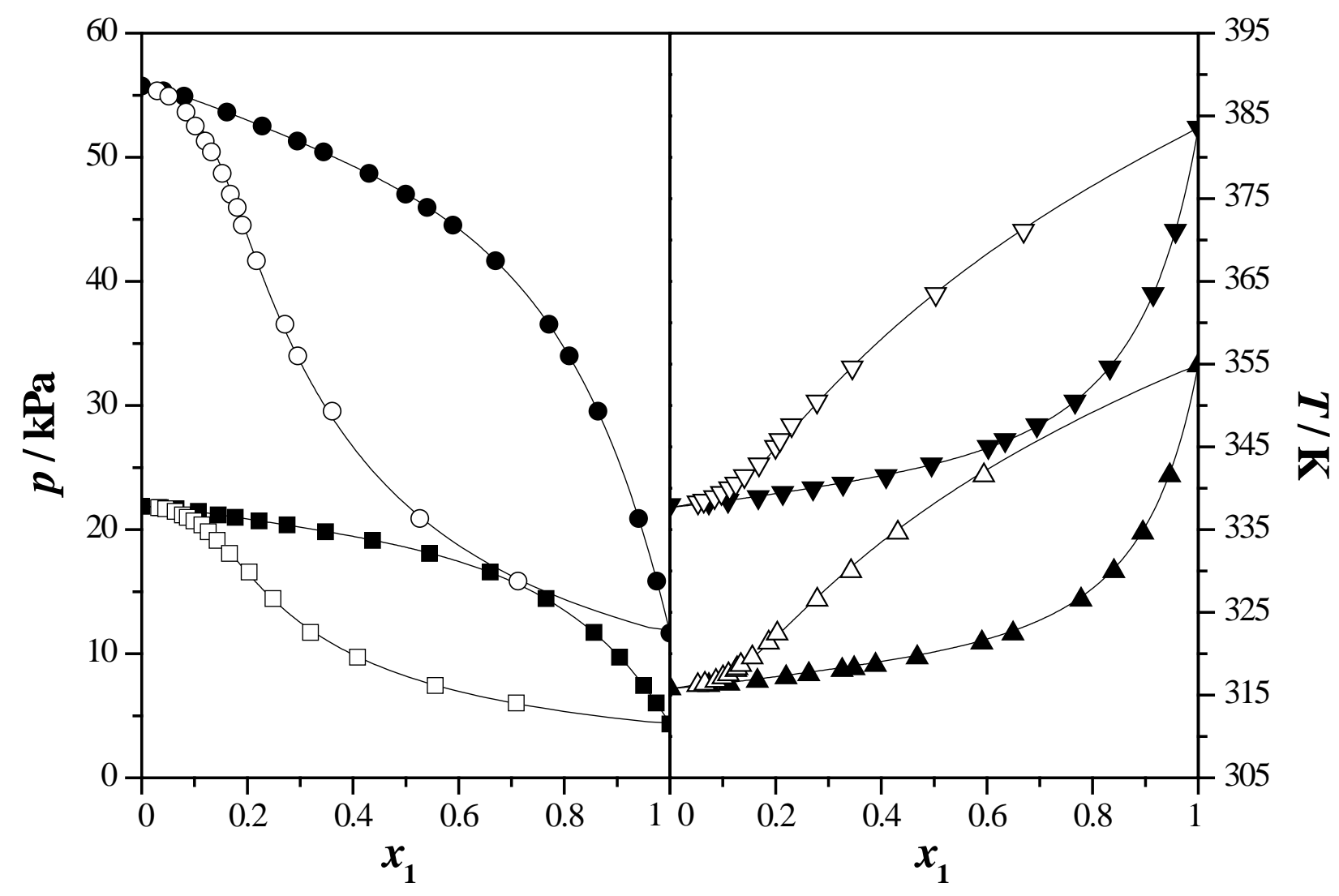

Fig. 4. $p-x_{1}-y_{1}$ and $T-x_{1}-y_{1}$ diagrams for the binary mixture ethyl isobutyrate (1) + methanol (2): $(\boldsymbol{\square}, \square)$ experimental data at $T=303.15 \mathrm{~K}$; $(\mathbf{O}, \bigcirc)$ experimental data at $T=323.15 \mathrm{~K}$; $(\boldsymbol{\Delta}, \triangle)$ experimental data at $p=40.000 \mathrm{kPa} ;(\boldsymbol{\nabla}, \nabla)$ experimental data at $p=101.325 \mathrm{kPa}$; (—) Wilson correlation. 


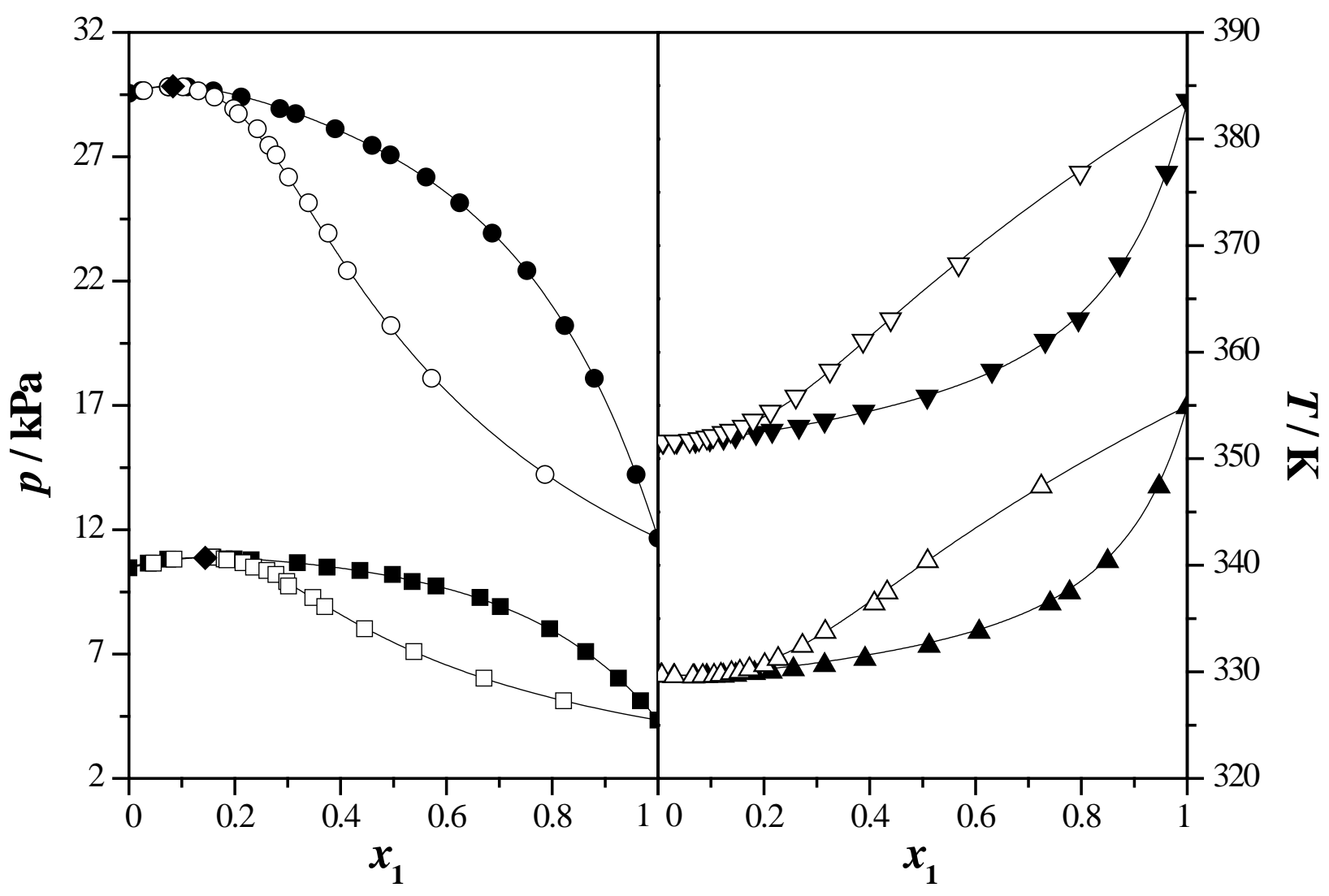

Fig. 5. $p-x_{1}-y_{1}$ and $T-x_{1}-y_{1}$ diagrams for the binary mixture ethyl isobutyrate (1) + ethanol (2): $(\boldsymbol{\square}, \square)$ experimental data at $T=303.15 \mathrm{~K} ;(\mathbf{O}, \bigcirc)$ experimental data at $T=323.15 \mathrm{~K} ;(\boldsymbol{\Delta}, \triangle)$ experimental data at $p=40.000 \mathrm{kPa} ;(\boldsymbol{\nabla}, \nabla)$ experimental data at $p=101.325 \mathrm{kPa}$; $(\diamond)$ calculated azeotropes; (-) Wilson correlation. 


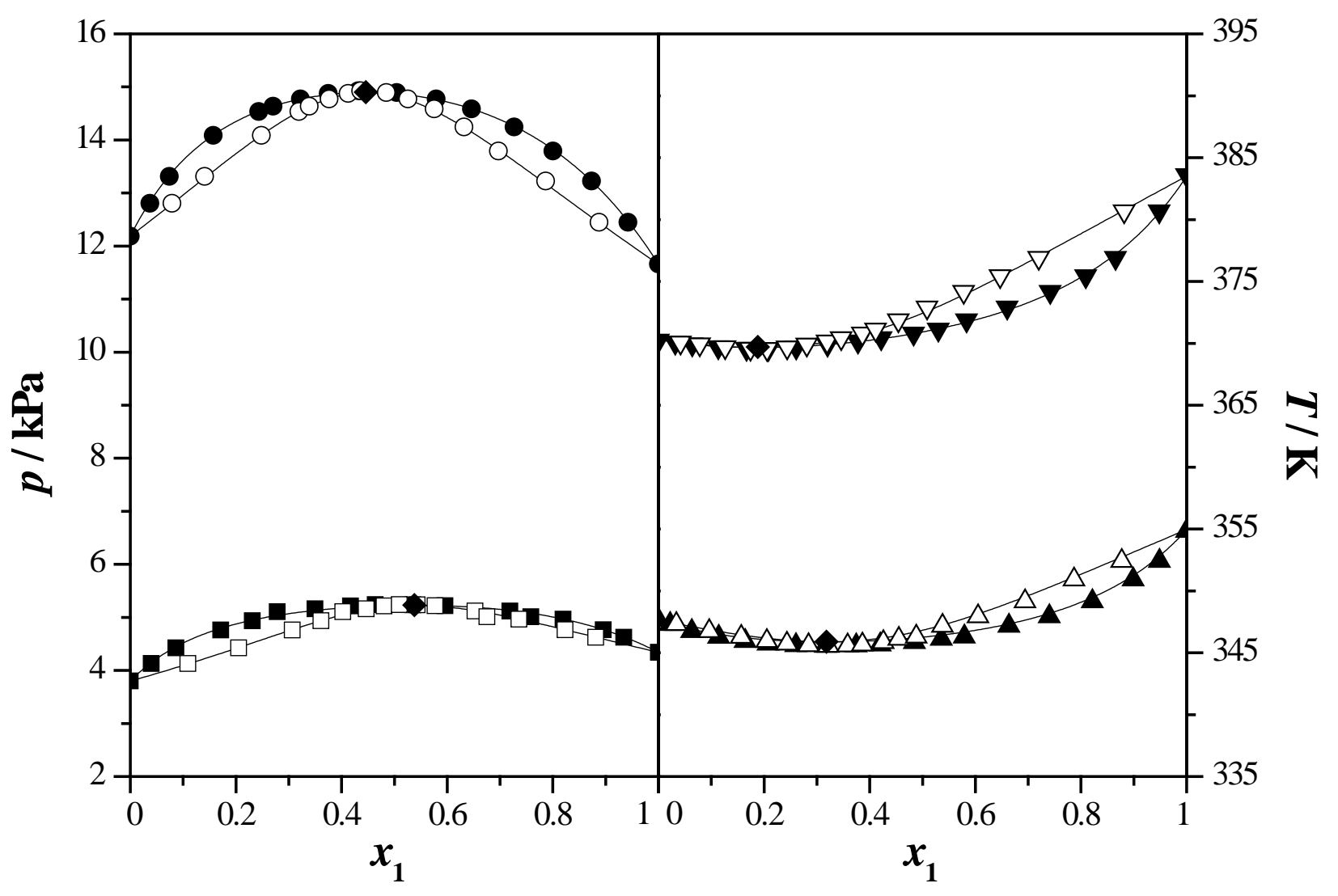

Fig. 6. $p-x_{1}-y_{1}$ and $T-x_{1}-y_{1}$ diagrams for the binary mixture ethyl isobutyrate (1) +1 -propanol (2): $(\boldsymbol{\square}, \square)$ experimental data at $T=303.15 \mathrm{~K}$; $(\mathbf{O}, \bigcirc)$ experimental data at $T=323.15 \mathrm{~K}$; $(\boldsymbol{\Lambda}, \triangle)$ experimental data at $p=40.000 \mathrm{kPa} ;(\boldsymbol{\nabla}, \nabla)$ experimental data at $p=101.325 \mathrm{kPa}$; $(\diamond)$ calculated azeotropes; $(-)$ Wilson correlation. 


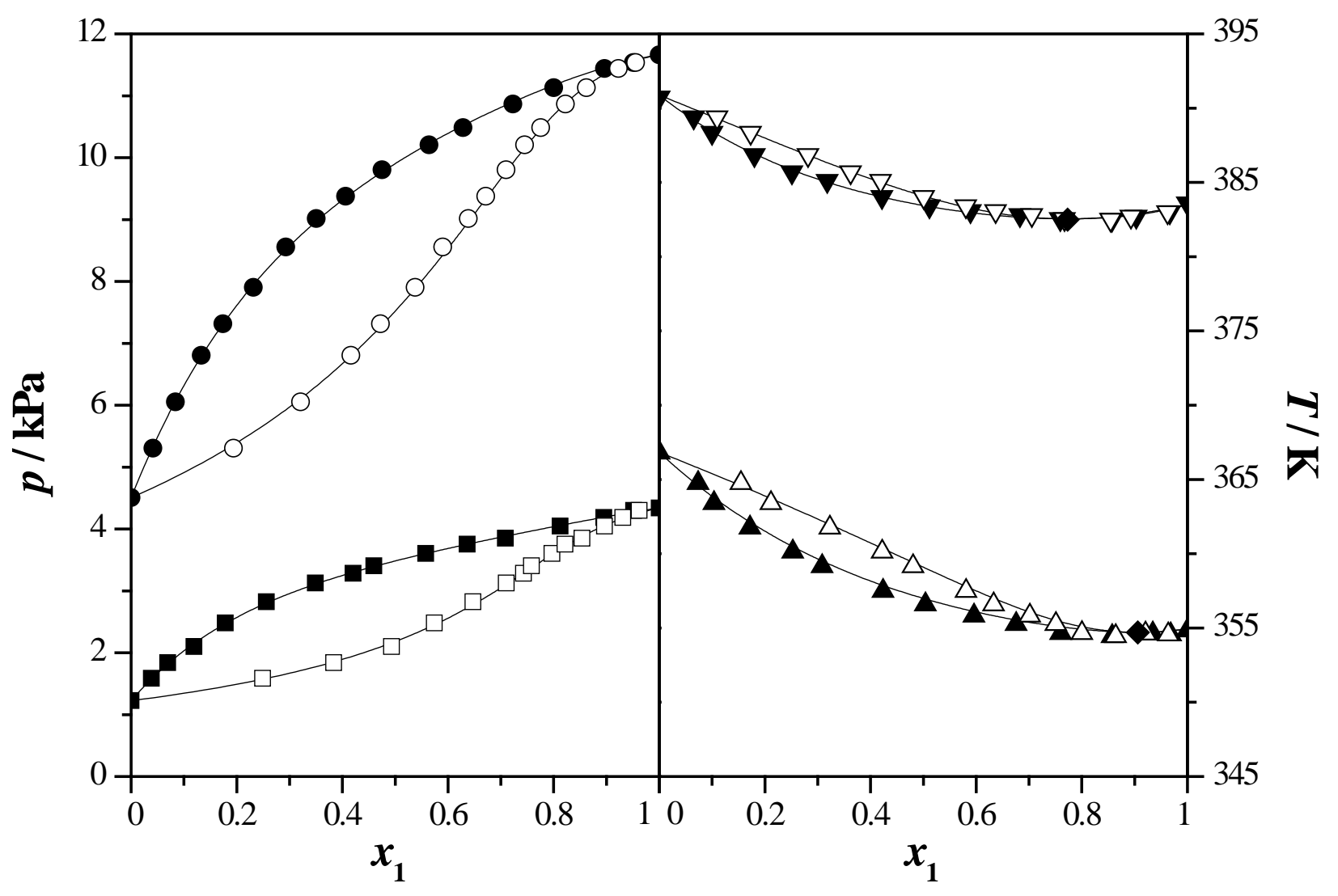

Fig. 7. $p-x_{1}-y_{1}$ and $T-x_{1}-y_{1}$ diagrams for the binary mixture ethyl isobutyrate (1) +1 -butanol (2): $(\boldsymbol{\square}, \square)$ experimental data at $T=303.15 \mathrm{~K}$; $(\mathbf{O}, \bigcirc)$ experimental data at $T=323.15 \mathrm{~K}$; $(\boldsymbol{\Delta}, \triangle)$ experimental data at $p=40.000 \mathrm{kPa} ;(\boldsymbol{\nabla}, \nabla)$ experimental data at $p=101.325 \mathrm{kPa}$; $(\diamond)$ calculated azeotropes; $(-)$ Wilson correlation. 


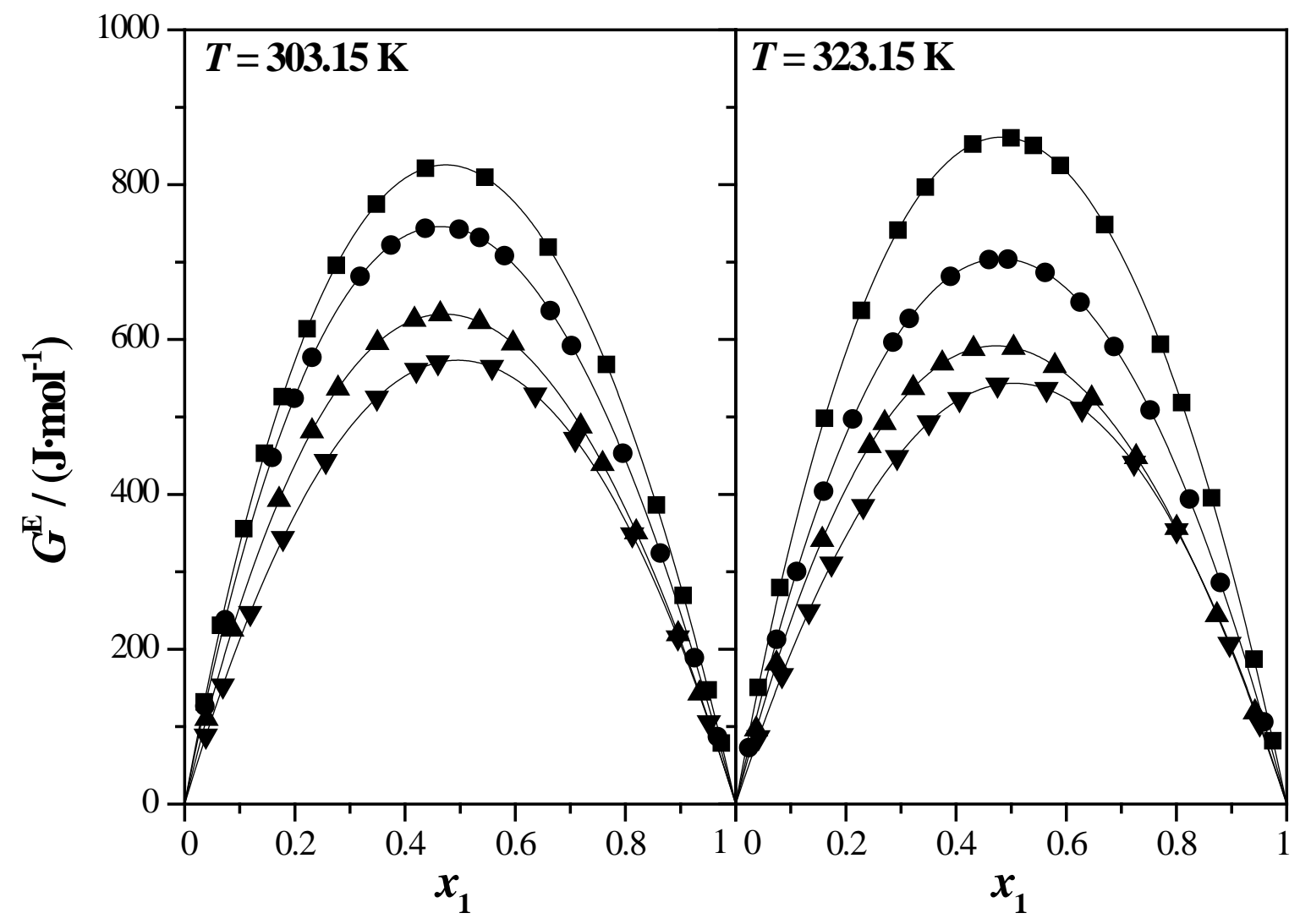

Fig. 8. Calculated excess Gibbs functions, $G^{\mathrm{E}}$, as a function of the mole fraction, $x_{1}$, at working temperatures for the binary mixtures ethyl isobutyrate (1) + alkanol (2):(ם) methanol; (O) ethanol; ( $\mathbf{\Delta})$ 1-propanol; ( $\boldsymbol{\nabla})$ 1-butanol; (-) Wilson equation. 


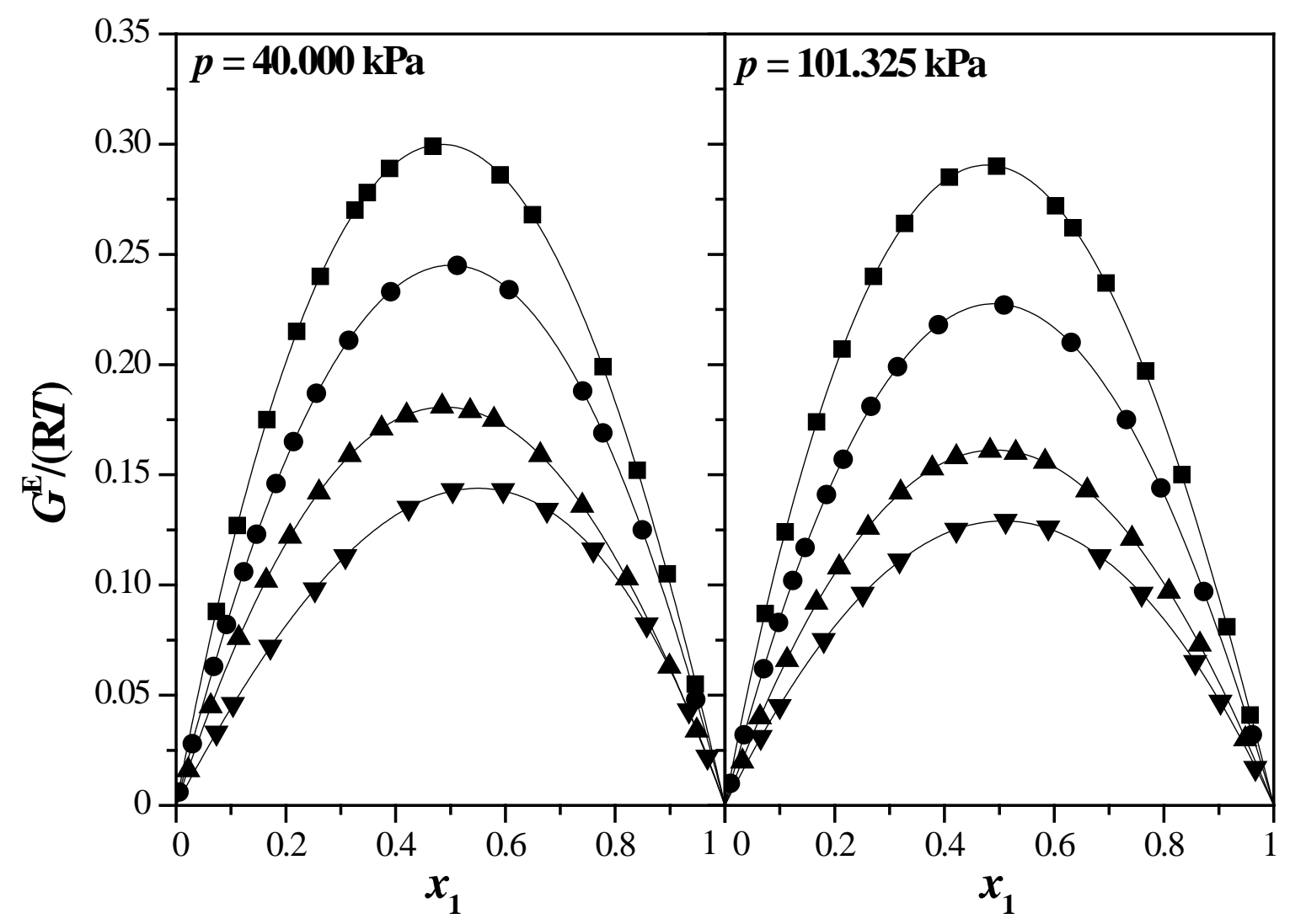

Fig. 9. Calculated reduced excess Gibbs functions, $G^{\mathrm{E}}$, as a function of the mole fraction, $x_{1}$, at working pressures for the binary mixtures ethyl isobutyrate (1) + alkanol (2):(ם) methanol; (O) ethanol; ( $\mathbf{\Delta})$ 1-propanol; ( $\boldsymbol{\nabla})$ 1-butanol; (-) Wilson equation. 


\section{Vapour-liquid equilibrium and excess properties of the binary mixtures formed by ethyl isobutyrate and n-alkanols}

Najla Ben Mahdoui ${ }^{\dagger \ddagger}$, Raouia Abidi ${ }^{\dagger \ddagger}$, Héctor Artigas ${ }^{\ddagger}$, Monia Hichri ${ }^{\dagger{ }^{*}}$, Carlos Lafuente ${ }^{\ddagger}$

‡ Departamento de Química Física, Facultad de Ciencias, Universidad de Zaragoza, 50009 Zaragoza, Spain

† Université de Tunis EL Manar, Faculté des Sciences, Laboratoire des Matériaux, Cristallochimie et Thermodynamique Appliquée, LR15ES01, Département de Chimie, 2092 Tunis, Tunisia

*Corresponding author. Tel: 0021698559305, E-mail address: monia.hichri@fst.utm.tn 
TABLE S1. Experimental densities, $\rho$, and calculated excess volumes, $V^{\mathrm{E}}$, as function of the mole fraction, $x_{1}$, for ethyl isobutyrate (1) + n-alkanol (2) systems at $p=0.1 \mathrm{MPa}$ and at working temperatures. $^{a}$

\begin{tabular}{|c|c|c|c|c|c|}
\hline$x_{1}$ & $\rho /\left(\mathrm{g} \cdot \mathrm{cm}^{-3}\right)$ & $V^{\mathrm{E}} /\left(\mathrm{cm}^{3} \cdot \mathrm{mol}^{-1}\right)$ & $x_{1}$ & $\rho /\left(\mathrm{g} \cdot \mathrm{cm}^{-3}\right)$ & $V^{\mathrm{E}} /\left(\mathrm{cm}^{3} \cdot \mathrm{mol}^{-1}\right)$ \\
\hline \multicolumn{6}{|c|}{ Ethyl isobutyrate (1) + methanol (2) at $T=303.15 \mathrm{~K}$} \\
\hline 0.0000 & 0.78181 & & 0.6099 & 0.84661 & -0.1203 \\
\hline 0.0501 & 0.79358 & -0.0274 & 0.7030 & 0.85012 & -0.1056 \\
\hline 0.1028 & 0.80354 & -0.0523 & 0.8056 & 0.85331 & -0.0794 \\
\hline 0.1996 & 0.81736 & -0.0854 & 0.9046 & 0.85588 & -0.0471 \\
\hline 0.3110 & 0.82869 & -0.1125 & 0.9538 & 0.85698 & -0.0251 \\
\hline 0.4038 & 0.83574 & -0.1262 & 1.0000 & 0.85792 & \\
\hline 0.4990 & 0.84141 & -0.1286 & & & \\
\hline \multicolumn{6}{|c|}{ Ethyl isobutyrate (1) + methanol (2) at $T=323.15 \mathrm{~K}$} \\
\hline 0.0000 & 0.76261 & & 0.6099 & 0.82484 & -0.0856 \\
\hline 0.0501 & 0.77385 & -0.0202 & 0.7030 & 0.82830 & -0.0765 \\
\hline 0.1028 & 0.78336 & -0.0378 & 0.8056 & 0.83144 & -0.0561 \\
\hline 0.1996 & 0.79663 & -0.0637 & 0.9046 & 0.83398 & -0.0308 \\
\hline 0.3110 & 0.80748 & -0.0802 & 0.9538 & 0.83508 & -0.0147 \\
\hline 0.4038 & 0.81425 & -0.0867 & 1.0000 & 0.83605 & \\
\hline 0.4990 & 0.81976 & -0.0895 & & & \\
\hline \multicolumn{6}{|c|}{ Ethyl isobutyrate (1) + ethanol (2) at $T=303.15 \mathrm{~K}$} \\
\hline 0.0000 & 0.78078 & & 0.6052 & 0.84031 & 0.0670 \\
\hline 0.0519 & 0.78931 & 0.0061 & 0.6952 & 0.84511 & 0.0571 \\
\hline 0.0865 & 0.79440 & 0.0123 & 0.7995 & 0.85004 & 0.0390 \\
\hline 0.1972 & 0.80819 & 0.0362 & 0.8912 & 0.85389 & 0.0195 \\
\hline 0.2954 & 0.81804 & 0.0564 & 0.9505 & 0.85615 & 0.0089 \\
\hline 0.3959 & 0.82646 & 0.0701 & 1.0000 & 0.85792 & \\
\hline 0.4964 & 0.83364 & 0.0727 & & & \\
\hline \multicolumn{6}{|c|}{ Ethyl isobutyrate (1) + ethanol (2) at $T=323.15 \mathrm{~K}$} \\
\hline 0.0000 & 0.76361 & & 0.6052 & 0.81910 & 0.1259 \\
\hline 0.0519 & 0.77156 & 0.0130 & 0.6952 & 0.82367 & 0.1108 \\
\hline 0.0865 & 0.77629 & 0.0251 & 0.7995 & 0.82838 & 0.0825 \\
\hline 0.1972 & 0.78909 & 0.0663 & 0.8912 & 0.83207 & 0.0519 \\
\hline 0.2954 & 0.79821 & 0.1026 & 0.9505 & 0.83428 & 0.0270 \\
\hline 0.3959 & 0.80606 & 0.1266 & 1.0000 & 0.83605 & \\
\hline 0.4964 & 0.81282 & 0.1316 & & & \\
\hline
\end{tabular}


TABLE S1. Continuation

\begin{tabular}{|c|c|c|c|c|c|}
\hline$x_{1}$ & $\rho /\left(\mathrm{g} \cdot \mathrm{cm}^{-3}\right)$ & $V^{\mathrm{E}} /\left(\mathrm{cm}^{3} \cdot \mathrm{mol}^{-1}\right)$ & $x_{1}$ & $\rho /\left(\mathrm{g} \cdot \mathrm{cm}^{-3}\right)$ & $V^{\mathrm{E}} /\left(\mathrm{cm}^{3} \cdot \mathrm{mol}^{-1}\right)$ \\
\hline \multicolumn{6}{|c|}{ Ethyl isobutyrate (1) + 1-propanol (2) at $T=303.15 \mathrm{~K}$} \\
\hline 0.0000 & 0.79553 & & 0.6030 & 0.84051 & 0.0858 \\
\hline 0.0528 & 0.80111 & 0.0092 & 0.7040 & 0.84554 & 0.0733 \\
\hline 0.1073 & 0.80638 & 0.0211 & 0.8014 & 0.84997 & 0.0541 \\
\hline 0.2033 & 0.81465 & 0.0491 & 0.9021 & 0.85416 & 0.0289 \\
\hline 0.2978 & 0.82183 & 0.0736 & 0.9546 & 0.85621 & 0.0150 \\
\hline 0.3984 & 0.82864 & 0.0900 & 1.0000 & 0.85792 & \\
\hline 0.5020 & 0.83496 & 0.0922 & & & \\
\hline \multicolumn{6}{|c|}{ Ethyl isobutyrate (1) + 1-propanol (2) at $T=323.15 \mathrm{~K}$} \\
\hline 0.0000 & 0.77909 & & 0.6030 & 0.81980 & 0.1401 \\
\hline 0.0528 & 0.78412 & 0.0174 & 0.7040 & 0.82442 & 0.1240 \\
\hline 0.1073 & 0.78885 & 0.0403 & 0.8014 & 0.82853 & 0.0969 \\
\hline 0.2033 & 0.79629 & 0.0825 & 0.9021 & 0.83243 & 0.0610 \\
\hline 0.2978 & 0.80276 & 0.1184 & 0.9546 & 0.83437 & 0.0344 \\
\hline 0.3984 & 0.80896 & 0.1397 & 1.0000 & 0.83605 & \\
\hline 0.5020 & 0.81472 & 0.1461 & & & \\
\hline \multicolumn{6}{|c|}{ Ethyl isobutyrate (1) + 1-butanol (2) at $T=303.15 \mathrm{~K}$} \\
\hline 0.0000 & 0.80191 & & 0.6160 & 0.84042 & 0.1099 \\
\hline 0.0461 & 0.80551 & 0.0122 & 0.7116 & 0.84513 & 0.0946 \\
\hline 0.1084 & 0.81012 & 0.0306 & 0.8062 & 0.84955 & 0.0706 \\
\hline 0.2062 & 0.81680 & 0.0678 & 0.9025 & 0.85381 & 0.0404 \\
\hline 0.2976 & 0.82262 & 0.0952 & 0.9454 & 0.85563 & 0.0245 \\
\hline 0.4024 & 0.82887 & 0.1131 & 1.0000 & 0.85792 & \\
\hline 0.5081 & 0.83478 & 0.1164 & & & \\
\hline \multicolumn{6}{|c|}{ Ethyl isobutyrate (1) + 1-butanol (2) at $T=323.15 \mathrm{~K}$} \\
\hline 0.0000 & 0.78662 & & 0.6160 & 0.82031 & 0.1550 \\
\hline 0.0461 & 0.78973 & 0.0206 & 0.7116 & 0.82448 & 0.1384 \\
\hline 0.1084 & 0.79371 & 0.0520 & 0.8062 & 0.82841 & 0.1110 \\
\hline 0.2062 & 0.79953 & 0.1000 & 0.9025 & 0.83223 & 0.0715 \\
\hline 0.2976 & 0.80459 & 0.1382 & 0.9454 & 0.83392 & 0.0427 \\
\hline 0.4024 & 0.81011 & 0.1569 & 1.0000 & 0.83605 & \\
\hline 0.5081 & 0.81533 & 0.1617 & & & \\
\hline
\end{tabular}

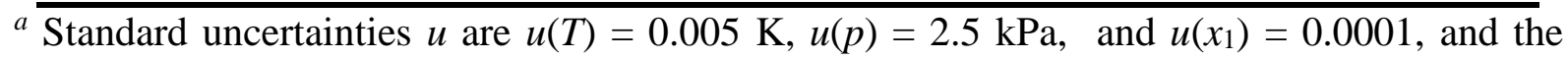
combined expanded uncertainty $U_{\mathrm{c}}$ is $U_{\mathrm{c}}(\rho)=2 \cdot 10^{-4} \mathrm{~g} \cdot \mathrm{cm}^{-3}$ with a 0.95 level of confidence $(\mathrm{k}=2)$. 
TABLE S2. Excess enthalpies, $H^{\mathrm{E}}$, as function of the mole fraction, $x_{1}$, for ethyl isobutyrate $(1)+$ n-alkanol (2) systems at $p=0.1 \mathrm{MPa}$ and at working temperatures. ${ }^{a}$

\begin{tabular}{|c|c|c|c|c|c|}
\hline$x_{1}$ & $H^{\mathrm{E}} /\left(\mathrm{J} \cdot \mathrm{mol}^{-1}\right)$ & $x_{1}$ & $H^{\mathrm{E}} /\left(\mathrm{J} \cdot \mathrm{mol}^{-1}\right)$ & $x_{1}$ & $H^{\mathrm{E}} /\left(\mathrm{J} \cdot \mathrm{mol}^{-1}\right)$ \\
\hline \multicolumn{6}{|c|}{ Ethyl isobutyrate (1) + methanol (2) at $T=303.15 \mathrm{~K}$} \\
\hline 0.046 & 110 & 0.383 & 591 & 0.771 & 632 \\
\hline 0.094 & 200 & 0.480 & 671 & 0.874 & 454 \\
\hline 0.192 & 363 & 0.579 & 715 & 0.925 & 299 \\
\hline 0.289 & 488 & 0.677 & 708 & & \\
\hline \multicolumn{6}{|c|}{ Ethyl isobutyrate (1) + methanol (2) at $T=323.15 \mathrm{~K}$} \\
\hline 0.046 & 169 & 0.383 & 985 & 0.771 & 955 \\
\hline 0.094 & 320 & 0.480 & 1098 & 0.874 & 627 \\
\hline 0.192 & 594 & 0.579 & 1150 & 0.925 & 399 \\
\hline 0.289 & 813 & 0.677 & 1112 & & \\
\hline \multicolumn{6}{|c|}{ Ethyl isobutyrate (1) + ethanol (2) at $T=303.15 \mathrm{~K}$} \\
\hline 0.046 & 194 & 0.388 & 1067 & 0.796 & 931 \\
\hline 0.094 & 371 & 0.491 & 1172 & 0.899 & 566 \\
\hline 0.191 & 671 & 0.592 & 1195 & 0.946 & 326 \\
\hline 0.291 & 905 & 0.689 & 1137 & & \\
\hline \multicolumn{6}{|c|}{ Ethyl isobutyrate (1) + ethanol (2) at $T=323.15 \mathrm{~K}$} \\
\hline 0.046 & 229 & 0.388 & 1260 & 0.796 & 1061 \\
\hline 0.094 & 438 & 0.491 & 1377 & 0.899 & 643 \\
\hline 0.191 & 791 & 0.592 & 1392 & 0.946 & 366 \\
\hline 0.291 & 1070 & 0.689 & 1293 & & \\
\hline \multicolumn{6}{|c|}{ Ethyl isobutyrate (1) + 1-propanol (2) at $T=303.15 \mathrm{~K}$} \\
\hline 0.045 & 217 & 0.389 & 1206 & 0.792 & 1018 \\
\hline 0.094 & 420 & 0.488 & 1318 & 0.894 & 620 \\
\hline 0.192 & 754 & 0.592 & 1331 & 0.946 & 338 \\
\hline 0.289 & 1008 & 0.691 & 1240 & & \\
\hline \multicolumn{6}{|c|}{ Ethyl isobutyrate (1) + 1-propanol (2) at $T=323.15 \mathrm{~K}$} \\
\hline 0.045 & 249 & 0.389 & 1397 & 0.792 & 1138 \\
\hline 0.094 & 485 & 0.488 & 1518 & 0.894 & 691 \\
\hline 0.192 & 887 & 0.592 & 1526 & 0.946 & 378 \\
\hline 0.289 & 1186 & 0.691 & 1405 & & \\
\hline
\end{tabular}


TABLE S2. Continuation

\begin{tabular}{|c|c|c|c|c|c|}
\hline$x_{1}$ & $H^{\mathrm{E}} /\left(\mathrm{J} \cdot \mathrm{mol}^{-1}\right)$ & $x_{1}$ & $H^{\mathrm{E}} /\left(\mathrm{J} \cdot \mathrm{mol}^{-1}\right)$ & $x_{1}$ & $H^{\mathrm{E}} /\left(\mathrm{J} \cdot \mathrm{mol}^{-1}\right)$ \\
\hline \multicolumn{6}{|c|}{ Ethyl isobutyrate (1) + 1-butanol (2) at $T=303.15 \mathrm{~K}$} \\
\hline 0.043 & 233 & 0.389 & 1289 & 0.793 & 1087 \\
\hline 0.093 & 456 & 0.488 & 1395 & 0.897 & 664 \\
\hline 0.190 & 819 & 0.590 & 1414 & 0.950 & 352 \\
\hline 0.291 & 1096 & 0.691 & 1331 & & \\
\hline \multicolumn{6}{|c|}{ Ethyl isobutyrate (1) + 1-butanol (2) at $T=323.15 \mathrm{~K}$} \\
\hline 0.043 & 258 & 0.389 & 1437 & 0.793 & 1173 \\
\hline 0.093 & 504 & 0.488 & 1549 & 0.897 & 710 \\
\hline 0.190 & 908 & 0.590 & 1559 & 0.950 & 386 \\
\hline 0.291 & 1227 & 0.691 & 1442 & & \\
\hline
\end{tabular}

${ }^{a}$ Standard uncertainties $u$ are $u(T)=0.0002 \mathrm{~K}, u(p)=2.5 \mathrm{kPa}$, and $u\left(x_{1}\right)=0.001$, and the combined expanded uncertainty $U_{\mathrm{c}}$ is $U_{\mathrm{c}}\left(H^{\mathrm{E}}\right)=1 \%$ with a 0.95 level of confidence $(\mathrm{k}=2)$. 
Table S3. Isothermal VLE data for ethyl isobutyrate (1) + n-alkanol (2) systems at several temperatures, $T$ : experimental pressure, $p$, liquid-phase, $x_{1}$, and vapor-phase, $y_{1}$ mole fractions, calculated activity coefficients $\gamma_{1}$, and calculated excess Gibbs functions, $G^{\mathrm{E}} \cdot{ }^{a}$

\begin{tabular}{|c|c|c|c|c|c|}
\hline$p / \mathrm{kPa}$ & $x_{1}$ & $y_{1}$ & $\gamma_{1}$ & $\gamma_{2}$ & $G^{\mathrm{E}} /\left(\mathrm{J} \cdot \mathrm{mol}^{-1}\right)$ \\
\hline \multicolumn{6}{|c|}{ Ethyl isobutyrate (1) + methanol (2) at $T=303.15 \mathrm{~K}$} \\
\hline 21.880 & 0.0000 & 0.0000 & & & \\
\hline 21.765 & 0.0356 & 0.0321 & 4.020 & 1.003 & 131.8 \\
\hline 21.675 & 0.0652 & 0.0455 & 3.565 & 1.009 & 230.7 \\
\hline 21.455 & 0.1073 & 0.0634 & 3.060 & 1.024 & 355.6 \\
\hline 21.185 & 0.1451 & 0.0775 & 2.710 & 1.042 & 453.2 \\
\hline 20.975 & 0.1773 & 0.0867 & 2.468 & 1.061 & 526.2 \\
\hline 20.690 & 0.2225 & 0.0992 & 2.193 & 1.093 & 613.9 \\
\hline 20.380 & 0.2753 & 0.1139 & 1.942 & 1.137 & 695.7 \\
\hline 19.820 & 0.3483 & 0.1262 & 1.683 & 1.213 & 774.8 \\
\hline 19.125 & 0.4369 & 0.1429 & 1.459 & 1.330 & 821.3 \\
\hline 18.075 & 0.5450 & 0.1663 & 1.273 & 1.517 & 809.6 \\
\hline 16.575 & 0.6600 & 0.2034 & 1.143 & 1.786 & 719.2 \\
\hline 14.445 & 0.7657 & 0.2487 & 1.065 & 2.125 & 567.6 \\
\hline 11.710 & 0.8563 & 0.3195 & 1.024 & 2.516 & 386.2 \\
\hline 9.715 & 0.9048 & 0.4089 & 1.011 & 2.778 & 269.5 \\
\hline 7.440 & 0.9503 & 0.5558 & 1.003 & 3.067 & 147.4 \\
\hline 6.025 & 0.9741 & 0.7092 & 1.001 & 3.238 & 78.7 \\
\hline 4.340 & 1.0000 & 1.0000 & & & \\
\hline \multicolumn{6}{|c|}{ Ethyl isobutyrate (1) + methanol (2) at $T=323.15 \mathrm{~K}$} \\
\hline 55.735 & 0.0000 & 0.0000 & & & \\
\hline 55.350 & 0.0410 & 0.0294 & 3.642 & 1.003 & 150.7 \\
\hline 54.915 & 0.0804 & 0.0513 & 3.182 & 1.012 & 279.5 \\
\hline 53.645 & 0.1611 & 0.0840 & 2.512 & 1.045 & 498.2 \\
\hline 52.510 & 0.2282 & 0.1016 & 2.132 & 1.087 & 637.7 \\
\hline 51.310 & 0.2947 & 0.1205 & 1.855 & 1.142 & 741.1 \\
\hline 50.425 & 0.3442 & 0.1322 & 1.694 & 1.192 & 796.7 \\
\hline 48.695 & 0.4304 & 0.1525 & 1.479 & 1.298 & 852.3 \\
\hline 47.025 & 0.4996 & 0.1678 & 1.350 & 1.406 & 860.5 \\
\hline 45.960 & 0.5405 & 0.1810 & 1.287 & 1.480 & 850.5 \\
\hline 44.530 & 0.5891 & 0.1905 & 1.223 & 1.581 & 824.7 \\
\hline 41.650 & 0.6697 & 0.2175 & 1.140 & 1.783 & 748.5 \\
\hline 36.535 & 0.7711 & 0.2710 & 1.066 & 2.119 & 593.9 \\
\hline
\end{tabular}


Table S3. Continuation.

\begin{tabular}{|c|c|c|c|c|c|}
\hline$p / \mathrm{kPa}$ & $x_{1}$ & $y_{1}$ & $\gamma_{1}$ & $\gamma_{2}$ & $G^{\mathrm{E}} /\left(\mathrm{J} \cdot \mathrm{mol}^{-1}\right)$ \\
\hline 33.985 & 0.8095 & 0.2955 & 1.045 & 2.279 & 518.3 \\
\hline 29.535 & 0.8637 & 0.3606 & 1.023 & 2.543 & 395.3 \\
\hline 20.890 & 0.9408 & 0.5266 & 1.004 & 3.021 & 187.1 \\
\hline 15.845 & 0.9751 & 0.7126 & 1.001 & 3.284 & 81.6 \\
\hline 11.660 & 1.0000 & 1.0000 & & & \\
\hline \multicolumn{6}{|c|}{ Ethyl isobutyrate (1) + ethanol (2) at $T=303.15 \mathrm{~K}$} \\
\hline 10.465 & 0.0000 & 0.0000 & & & \\
\hline 10.650 & 0.0369 & 0.0464 & 3.611 & 1.003 & 126.7 \\
\hline 10.815 & 0.0736 & 0.0851 & 3.135 & 1.011 & 238.1 \\
\hline 10.895 & 0.1589 & 0.1564 & 2.391 & 1.048 & 447.6 \\
\hline 10.825 & 0.1988 & 0.1799 & 2.153 & 1.072 & 524.1 \\
\hline 10.785 & 0.2311 & 0.1850 & 1.994 & 1.094 & 576.9 \\
\hline 10.670 & 0.3183 & 0.2157 & 1.672 & 1.170 & 681.6 \\
\hline 10.495 & 0.3745 & 0.2358 & 1.522 & 1.229 & 721.9 \\
\hline 10.360 & 0.4368 & 0.2607 & 1.392 & 1.306 & 743.6 \\
\hline 10.200 & 0.4983 & 0.2778 & 1.292 & 1.395 & 742.5 \\
\hline 9.915 & 0.5355 & 0.2982 & 1.242 & 1.455 & 731.6 \\
\hline 9.735 & 0.5804 & 0.3016 & 1.191 & 1.534 & 708.3 \\
\hline 9.270 & 0.6634 & 0.3475 & 1.116 & 1.706 & 637.2 \\
\hline 8.905 & 0.7020 & 0.3701 & 1.089 & 1.799 & 592.1 \\
\hline 8.015 & 0.7951 & 0.4454 & 1.041 & 2.060 & 453.0 \\
\hline 7.100 & 0.8634 & 0.5386 & 1.018 & 2.295 & 324.2 \\
\hline 6.030 & 0.9250 & 0.6712 & 1.005 & 2.546 & 188.9 \\
\hline 5.115 & 0.9668 & 0.8215 & 1.001 & 2.741 & 86.9 \\
\hline 4.340 & 1.0000 & 1.0000 & & & \\
\hline \multicolumn{6}{|c|}{ Ethyl isobutyrate (1) + ethanol (2) at $T=323.15 \mathrm{~K}$} \\
\hline 29.545 & 0.0000 & 0.0000 & & & \\
\hline 29.660 & 0.0238 & 0.0281 & 3.010 & 1.001 & 72.7 \\
\hline 29.810 & 0.0745 & 0.0748 & 2.615 & 1.008 & 212.6 \\
\hline 29.805 & 0.1107 & 0.1018 & 2.389 & 1.017 & 300.4 \\
\hline 29.645 & 0.1596 & 0.1313 & 2.137 & 1.035 & 404.0 \\
\hline 29.400 & 0.2123 & 0.1616 & 1.919 & 1.061 & 497.2 \\
\hline 28.935 & 0.2855 & 0.1982 & 1.685 & 1.108 & 596.6 \\
\hline 28.725 & 0.3151 & 0.2069 & 1.608 & 1.130 & 627.3 \\
\hline 28.120 & 0.3899 & 0.2426 & 1.446 & 1.197 & 681.6 \\
\hline
\end{tabular}


Table S3. Continuation.

\begin{tabular}{|c|c|c|c|c|c|}
\hline$p / \mathrm{kPa}$ & $x_{1}$ & $y_{1}$ & $\gamma_{1}$ & $\gamma_{2}$ & $G^{\mathrm{E}} /\left(\mathrm{J} \cdot \mathrm{mol}^{-1}\right)$ \\
\hline 27.455 & 0.4598 & 0.2647 & 1.329 & 1.274 & 703.3 \\
\hline 27.070 & 0.4939 & 0.2783 & 1.282 & 1.317 & 703.9 \\
\hline 26.180 & 0.5617 & 0.3017 & 1.202 & 1.415 & 686.6 \\
\hline 25.145 & 0.6252 & 0.3395 & 1.143 & 1.523 & 648.2 \\
\hline 23.925 & 0.6866 & 0.3767 & 1.097 & 1.646 & 591.0 \\
\hline 22.415 & 0.7521 & 0.4130 & 1.060 & 1.800 & 508.8 \\
\hline 20.210 & 0.8237 & 0.4952 & 1.030 & 2.002 & 393.8 \\
\hline 18.090 & 0.8796 & 0.5720 & 1.014 & 2.190 & 286.0 \\
\hline 14.220 & 0.9588 & 0.7864 & 1.002 & 2.514 & 106.2 \\
\hline 11.660 & 1.0000 & 1.0000 & & & \\
\hline \multicolumn{6}{|c|}{ Ethyl isobutyrate (1) + 1-propanol (2) at $T=303.15 \mathrm{~K}$} \\
\hline 3.800 & 0.0000 & 0.0000 & & & \\
\hline 4.130 & 0.0395 & 0.1092 & 2.847 & 1.003 & 110.2 \\
\hline 4.425 & 0.0866 & 0.2051 & 2.491 & 1.012 & 225.6 \\
\hline 4.760 & 0.1715 & 0.3068 & 2.032 & 1.042 & 392.9 \\
\hline 4.935 & 0.2310 & 0.3611 & 1.804 & 1.074 & 481.7 \\
\hline 5.105 & 0.2784 & 0.4024 & 1.659 & 1.105 & 536.9 \\
\hline 5.160 & 0.3498 & 0.4468 & 1.488 & 1.161 & 595.7 \\
\hline 5.215 & 0.4171 & 0.4807 & 1.364 & 1.226 & 625.6 \\
\hline 5.240 & 0.4639 & 0.5096 & 1.294 & 1.277 & 632.7 \\
\hline 5.235 & 0.5352 & 0.5433 & 1.209 & 1.368 & 622.6 \\
\hline 5.220 & 0.5959 & 0.5773 & 1.151 & 1.458 & 595.1 \\
\hline 5.120 & 0.7189 & 0.6526 & 1.068 & 1.681 & 487.9 \\
\hline 5.010 & 0.7583 & 0.6751 & 1.050 & 1.767 & 439.5 \\
\hline 4.965 & 0.8195 & 0.7357 & 1.027 & 1.916 & 351.2 \\
\hline 4.765 & 0.8956 & 0.8234 & 1.009 & 2.134 & 219.5 \\
\hline 4.625 & 0.9345 & 0.8813 & 1.003 & 2.262 & 142.9 \\
\hline 4.340 & 1.0000 & 1.0000 & & & \\
\hline \multicolumn{6}{|c|}{ Ethyl isobutyrate (1) + 1-propanol (2) at $T=323.15 \mathrm{~K}$} \\
\hline 12.185 & 0.0000 & 0.0000 & & & \\
\hline 12.805 & 0.0374 & 0.0789 & 2.491 & 1.002 & 96.6 \\
\hline 13.315 & 0.0740 & 0.1407 & 2.280 & 1.007 & 181.5 \\
\hline 14.085 & 0.1571 & 0.2481 & 1.913 & 1.030 & 341.4 \\
\hline 14.535 & 0.2432 & 0.3193 & 1.648 & 1.069 & 462.7 \\
\hline 14.635 & 0.2705 & 0.3387 & 1.581 & 1.085 & 492.4 \\
\hline
\end{tabular}


Table S3. Continuation.

\begin{tabular}{|c|c|c|c|c|c|}
\hline$p / \mathrm{kPa}$ & $x_{1}$ & $y_{1}$ & $\gamma_{1}$ & $\gamma_{2}$ & $G^{\mathrm{E}} /\left(\mathrm{J} \cdot \mathrm{mol}^{-1}\right)$ \\
\hline 14.775 & 0.3221 & 0.3766 & 1.471 & 1.118 & 537.5 \\
\hline 14.875 & 0.3748 & 0.4125 & 1.378 & 1.158 & 569.2 \\
\hline 14.925 & 0.4316 & 0.4363 & 1.296 & 1.207 & 587.9 \\
\hline 14.895 & 0.5045 & 0.4848 & 1.212 & 1.280 & 589.4 \\
\hline 14.775 & 0.5790 & 0.5259 & 1.145 & 1.369 & 565.9 \\
\hline 14.585 & 0.6461 & 0.5756 & 1.098 & 1.462 & 524.0 \\
\hline 14.245 & 0.7268 & 0.6319 & 1.056 & 1.592 & 448.4 \\
\hline 13.790 & 0.8001 & 0.6971 & 1.029 & 1.731 & 356.8 \\
\hline 13.225 & 0.8732 & 0.7864 & 1.012 & 1.892 & 244.2 \\
\hline 12.450 & 0.9424 & 0.8875 & 1.002 & 2.070 & 118.5 \\
\hline 11.660 & 1.0000 & 1.0000 & & & \\
\hline \multicolumn{6}{|c|}{ Ethyl isobutyrate (1) + 1-butanol (2) at $T=303.15 \mathrm{~K}$} \\
\hline 1.225 & 0.0000 & 0.0000 & & & \\
\hline 1.585 & 0.0386 & 0.2489 & 2.380 & 1.002 & 88.2 \\
\hline 1.840 & 0.0694 & 0.3737 & 2.241 & 1.005 & 152.9 \\
\hline 2.100 & 0.1189 & 0.4929 & 2.047 & 1.015 & 246.7 \\
\hline 2.480 & 0.1786 & 0.5743 & 1.852 & 1.032 & 343.4 \\
\hline 2.825 & 0.2562 & 0.6475 & 1.649 & 1.066 & 443.1 \\
\hline 3.125 & 0.3490 & 0.7106 & 1.462 & 1.123 & 524.8 \\
\hline 3.285 & 0.4203 & 0.7430 & 1.350 & 1.180 & 560.6 \\
\hline 3.405 & 0.4597 & 0.7582 & 1.298 & 1.218 & 570.4 \\
\hline 3.605 & 0.5580 & 0.7969 & 1.191 & 1.331 & 564.4 \\
\hline 3.755 & 0.6363 & 0.8215 & 1.126 & 1.446 & 528.8 \\
\hline 3.850 & 0.7086 & 0.8539 & 1.080 & 1.577 & 471.5 \\
\hline 4.045 & 0.8124 & 0.8962 & 1.033 & 1.816 & 348.2 \\
\hline 4.185 & 0.8950 & 0.9312 & 1.010 & 2.065 & 215.1 \\
\hline 4.300 & 0.9517 & 0.9618 & 1.002 & 2.276 & 105.4 \\
\hline 4.340 & 1.0000 & 1.0000 & & & \\
\hline \multicolumn{6}{|c|}{ Ethyl isobutyrate (1) + 1-butanol (2) at $T=323.15 \mathrm{~K}$} \\
\hline 4.505 & 0.0000 & 0.0000 & & & \\
\hline 5.305 & 0.0415 & 0.1938 & 2.095 & 1.001 & 86.1 \\
\hline 6.055 & 0.0839 & 0.3210 & 1.964 & 1.006 & 166.3 \\
\hline 6.805 & 0.1328 & 0.4161 & 1.830 & 1.014 & 249.0 \\
\hline 7.315 & 0.1738 & 0.4724 & 1.731 & 1.025 & 310.4 \\
\hline 7.905 & 0.2315 & 0.5377 & 1.609 & 1.044 & 384.6 \\
\hline
\end{tabular}


Table S3. Continuation.

\begin{tabular}{cccccc}
\hline$p / \mathrm{kPa}$ & $x_{1}$ & $y_{1}$ & $\gamma_{1}$ & $\gamma_{2}$ & $G^{\mathrm{E}} /\left(\mathrm{J} \cdot \mathrm{mol}^{-1}\right)$ \\
\hline 8.555 & 0.2929 & 0.5901 & 1.498 & 1.071 & 447.9 \\
9.015 & 0.3508 & 0.6386 & 1.407 & 1.103 & 493.0 \\
9.375 & 0.4063 & 0.6716 & 1.333 & 1.140 & 522.8 \\
10.865 & 0.7228 & 0.8222 & 1.068 & 1.521 & 440.7 \\
11.130 & 0.8003 & 0.8622 & 1.036 & 1.680 & 353.5 \\
11.440 & 0.8965 & 0.9226 & 1.010 & 1.936 & 206.9 \\
11.535 & 0.9512 & 0.9552 & 1.002 & 2.120 & 104.1 \\
11.660 & 1.0000 & 1.0000 & & & \\
\hline
\end{tabular}

${ }^{a}$ Standard uncertainties $u$ are $u(T)=0.1 \mathrm{~K}, u(p)=0.1 \mathrm{kPa}, u\left(x_{1}\right)=0.002$, and $u\left(y_{1}\right)=0.002$. 
Table S4. Isobaric VLE data for ethyl isobutyrate (1) + n-alkanol (2) systems at several pressures, $p$ : experimental temperature, $T$, liquid-phase, $x_{1}$, and vapor-phase, $y_{1}$ mole fractions, calculated activity coefficients $\gamma_{i}$, and calculated reduced excess Gibbs functions, $G^{\mathrm{E}} /(\mathrm{R} T) .^{a}$

\begin{tabular}{|c|c|c|c|c|c|}
\hline$T / \mathrm{K}$ & $x_{1}$ & $y_{1}$ & $\gamma_{1}$ & $\gamma_{2}$ & $G^{\mathrm{E}} /(\mathrm{R} T)$ \\
\hline \multicolumn{6}{|c|}{ Ethyl isobutyrate (1) + methanol (2) at $p=40.000 \mathrm{kPa}$} \\
\hline 315.81 & 0.0000 & 0.0000 & & & \\
\hline 316.20 & 0.0734 & 0.0528 & 2.976 & 1.009 & 0.088 \\
\hline 316.37 & 0.1117 & 0.0662 & 2.679 & 1.019 & 0.127 \\
\hline 316.72 & 0.1655 & 0.0869 & 2.343 & 1.041 & 0.175 \\
\hline 317.13 & 0.2197 & 0.1004 & 2.078 & 1.071 & 0.215 \\
\hline 317.51 & 0.2629 & 0.1107 & 1.906 & 1.101 & 0.240 \\
\hline 318.01 & 0.3259 & 0.1250 & 1.702 & 1.154 & 0.270 \\
\hline 318.24 & 0.3487 & 0.1271 & 1.639 & 1.176 & 0.278 \\
\hline 318.63 & 0.3889 & 0.1342 & 1.541 & 1.218 & 0.289 \\
\hline 319.55 & 0.4680 & 0.1557 & 1.383 & 1.319 & 0.299 \\
\hline 321.35 & 0.5906 & 0.1866 & 1.210 & 1.528 & 0.286 \\
\hline 322.44 & 0.6493 & 0.2029 & 1.150 & 1.656 & 0.268 \\
\hline 326.52 & 0.7783 & 0.2788 & 1.057 & 2.020 & 0.199 \\
\hline 329.97 & 0.8405 & 0.3427 & 1.029 & 2.239 & 0.152 \\
\hline 334.63 & 0.8953 & 0.4314 & 1.012 & 2.451 & 0.105 \\
\hline 341.55 & 0.9463 & 0.5944 & 1.003 & 2.644 & 0.055 \\
\hline \multirow[t]{2}{*}{354.84} & 1.0000 & 1.0000 & & & \\
\hline & \multicolumn{5}{|c|}{ Ethyl isobutyrate (1) + methanol (2) at $p=101.325 \mathrm{kPa}$} \\
\hline 337.96 & 0.0000 & 0.0000 & & & \\
\hline 338.29 & 0.0734 & 0.0532 & 2.937 & 1.009 & 0.087 \\
\hline 338.50 & 0.1097 & 0.0641 & 2.650 & 1.019 & 0.124 \\
\hline 338.94 & 0.1672 & 0.0844 & 2.290 & 1.043 & 0.174 \\
\hline 339.43 & 0.2137 & 0.0975 & 2.063 & 1.069 & 0.207 \\
\hline 340.01 & 0.2706 & 0.1128 & 1.840 & 1.108 & 0.240 \\
\hline 340.56 & 0.3276 & 0.1247 & 1.663 & 1.157 & 0.264 \\
\hline 341.47 & 0.4090 & 0.1407 & 1.468 & 1.242 & 0.285 \\
\hline 342.89 & 0.4953 & 0.1682 & 1.316 & 1.357 & 0.290 \\
\hline 345.01 & 0.6027 & 0.1996 & 1.182 & 1.541 & 0.272 \\
\hline 345.84 & 0.6345 & 0.2079 & 1.151 & 1.606 & 0.262 \\
\hline 347.61 & 0.6946 & 0.2304 & 1.102 & 1.742 & 0.237 \\
\hline
\end{tabular}


Table S4. Continuation.

\begin{tabular}{|c|c|c|c|c|c|}
\hline$T / \mathrm{K}$ & $x_{1}$ & $y_{1}$ & $\gamma_{1}$ & $\gamma_{2}$ & $G^{\mathrm{E}} /\left(\mathrm{R}^{\prime}\right.$ \\
\hline 350.47 & 0.7667 & 0.2783 & 1.057 & 1.933 & 0.1 \\
\hline 354.59 & 0.8328 & 0.3450 & 1.028 & 2.132 & 0.1 \\
\hline 363.47 & 0.9148 & 0.5030 & 1.007 & 2.393 & 0.0 \\
\hline 371.12 & 0.9569 & 0.6695 & 1.002 & 2.511 & 0.0 \\
\hline 383.59 & 1.0000 & 1.0000 & & & \\
\hline \multicolumn{6}{|c|}{ Ethyl isobutyrate (1) + ethanol (2) at $p=40.000 \mathrm{kPa}$} \\
\hline 329.61 & 0.0000 & 0.0000 & & & \\
\hline 329.64 & 0.0056 & 0.0070 & 2.661 & 1.000 & 0.0 \\
\hline 329.58 & 0.0295 & 0.0310 & 2.534 & 1.001 & 0.0 \\
\hline 329.56 & 0.0685 & 0.0661 & 2.348 & 1.005 & 0.0 \\
\hline 329.60 & 0.0920 & 0.0844 & 2.247 & 1.009 & 0 . \\
\hline 329.63 & 0.1234 & 0.1056 & 2.123 & 1.016 & 0.1 \\
\hline 329.71 & 0.1465 & 0.1187 & 2.040 & 1.022 & 0.1 \\
\hline 329.87 & 0.1824 & 0.1389 & 1.923 & 1.034 & 0.1 \\
\hline 330.01 & 0.2141 & 0.1548 & 1.829 & 1.047 & \\
\hline 330.23 & 0.2557 & 0.1725 & 1.719 & 1.067 & 0.1 \\
\hline 330.62 & 0.3148 & 0.2013 & 1.584 & 1.102 & 0. \\
\hline 331.21 & 0.3911 & 0.2269 & 1.440 & 1.160 & 0.2 \\
\hline 332.44 & 0.5124 & 0.2728 & 1.267 & 1.287 & 0.2 \\
\hline 333.74 & 0.6066 & 0.3161 & 1.169 & 1.424 & 0.2 \\
\hline 336.41 & 0.7409 & 0.4085 & 1.072 & 1.696 & 0.1 \\
\hline 337.44 & 0.7775 & 0.4331 & 1.053 & 1.790 & 0.1 \\
\hline 340.39 & 0.8496 & 0.5095 & 1.024 & 2.005 & 0.1 \\
\hline 347.39 & 0.9470 & 0.7242 & 1.003 & 2.359 & \\
\hline 354.84 & 1.0000 & 1.0000 & & & \\
\hline
\end{tabular}

Ethyl isobutyrate (1) + ethanol (2) at $p=101.325 \mathrm{kPa}$

351.48 $0.0000 \quad 0.0000$

351.60

$0.0102 \quad 0.0086$

351.61

0.0350

0.0308

2.537

1.000

0.010

351.70

0.0705

0.0598

2.410

1.001

0.032

351.83

0.0978

0.0772

2.248

1.005

0.062

351.99

0.1237

0.0924

2.136

1.010

0.083

352.12

0.1462

0.1041

2.039

1.016

0.102

352.42

0.1850

0.1229

1.961

1.022

0.117

352.62

0.2157

0.1369

1.840

1.035

0.141

1.755

1.047

0.157 
Table S4. Continuation.

\begin{tabular}{|c|c|c|c|c|c|}
\hline$T / \mathrm{K}$ & $x_{1}$ & $y_{1}$ & $\gamma_{1}$ & $\gamma_{2}$ & $G^{\mathrm{E}} /(\mathrm{R} T)$ \\
\hline 353.01 & 0.2662 & 0.1609 & 1.631 & 1.071 & 0.181 \\
\hline 353.59 & 0.3145 & 0.1798 & 1.529 & 1.100 & 0.199 \\
\hline 354.41 & 0.3890 & 0.2121 & 1.398 & 1.154 & 0.218 \\
\hline 355.84 & 0.5085 & 0.2604 & 1.240 & 1.270 & 0.227 \\
\hline 358.26 & 0.6309 & 0.3247 & 1.129 & 1.434 & 0.210 \\
\hline 361.07 & 0.7317 & 0.3872 & 1.066 & 1.613 & 0.175 \\
\hline 363.10 & 0.7944 & 0.4397 & 1.038 & 1.748 & 0.144 \\
\hline 368.24 & 0.8727 & 0.5678 & 1.014 & 1.943 & 0.097 \\
\hline 376.83 & 0.9611 & 0.7979 & 1.001 & 2.185 & 0.032 \\
\hline 383.59 & 1.0000 & 1.0000 & & & \\
\hline \multicolumn{6}{|c|}{ Ethyl isobutyrate (1) +1 -propanol (2) at $p=40.000 \mathrm{kPa}$} \\
\hline 347.66 & 0.0000 & 0.0000 & & & \\
\hline 347.31 & 0.0221 & 0.0340 & 2.056 & 1.000 & 0.016 \\
\hline 346.74 & 0.0633 & 0.0963 & 1.925 & 1.003 & 0.045 \\
\hline 346.28 & 0.1141 & 0.1567 & 1.785 & 1.011 & 0.076 \\
\hline 345.94 & 0.1641 & 0.2052 & 1.667 & 1.022 & 0.102 \\
\hline 345.73 & 0.2075 & 0.2431 & 1.577 & 1.035 & 0.122 \\
\hline 345.60 & 0.2604 & 0.2840 & 1.481 & 1.055 & 0.142 \\
\hline 345.56 & 0.3164 & 0.3217 & 1.395 & 1.081 & 0.159 \\
\hline 345.58 & 0.3744 & 0.3583 & 1.318 & 1.114 & 0.171 \\
\hline 345.66 & 0.4198 & 0.3863 & 1.267 & 1.144 & 0.177 \\
\hline 345.85 & 0.4846 & 0.4257 & 1.203 & 1.193 & 0.181 \\
\hline 346.12 & 0.5358 & 0.4550 & 1.161 & 1.238 & 0.179 \\
\hline 346.30 & 0.5792 & 0.4881 & 1.130 & 1.281 & 0.175 \\
\hline 347.18 & 0.6635 & 0.5378 & 1.081 & 1.377 & 0.159 \\
\hline 347.95 & 0.7399 & 0.6050 & 1.047 & 1.481 & 0.136 \\
\hline 349.16 & 0.8216 & 0.6940 & 1.022 & 1.612 & 0.103 \\
\hline 350.92 & 0.8988 & 0.7870 & 1.007 & 1.758 & 0.063 \\
\hline 352.42 & 0.9485 & 0.8772 & 1.002 & 1.863 & 0.034 \\
\hline 354.84 & 1.0000 & 1.0000 & & & \\
\hline \multicolumn{6}{|c|}{ Ethyl isobutyrate (1) + 1-propanol (2) at $p=101.325 \mathrm{kPa}$} \\
\hline 370.21 & 0.0000 & 0.0000 & & & \\
\hline 370.07 & 0.0316 & 0.0418 & 1.865 & 1.001 & 0.020 \\
\hline 369.92 & 0.0639 & 0.0780 & 1.785 & 1.003 & 0.040 \\
\hline 369.69 & 0.1131 & 0.1262 & 1.676 & 1.009 & 0.066 \\
\hline
\end{tabular}


Table S4. Continuation.

\begin{tabular}{|c|c|c|c|c|c|}
\hline$T / \mathrm{K}$ & $x_{1}$ & $y_{1}$ & $\gamma_{1}$ & $\gamma_{2}$ & $G^{\mathrm{E}} /(\mathrm{R} T)$ \\
\hline 369.56 & 0.1666 & 0.1744 & 1.572 & 1.020 & 0.092 \\
\hline 369.54 & 0.2079 & 0.2054 & 1.502 & 1.031 & 0.108 \\
\hline 369.67 & 0.2609 & 0.2435 & 1.421 & 1.048 & 0.126 \\
\hline 369.91 & 0.3201 & 0.2809 & 1.344 & 1.072 & 0.142 \\
\hline 370.15 & 0.3777 & 0.3194 & 1.279 & 1.101 & 0.153 \\
\hline 370.42 & 0.4217 & 0.3461 & 1.236 & 1.126 & 0.158 \\
\hline 370.80 & 0.4829 & 0.3861 & 1.183 & 1.167 & 0.161 \\
\hline 371.11 & 0.5299 & 0.4111 & 1.149 & 1.203 & 0.160 \\
\hline 371.86 & 0.5835 & 0.4544 & 1.114 & 1.249 & 0.156 \\
\hline 372.89 & 0.6601 & 0.5086 & 1.074 & 1.325 & 0.143 \\
\hline 374.16 & 0.7419 & 0.5778 & 1.042 & 1.421 & 0.121 \\
\hline 375.42 & 0.8092 & 0.6469 & 1.023 & 1.513 & 0.097 \\
\hline 376.90 & 0.8654 & 0.7199 & 1.011 & 1.599 & 0.073 \\
\hline 380.66 & 0.9483 & 0.8819 & 1.002 & 1.742 & 0.030 \\
\hline 383.59 & 1.0000 & 1.0000 & & & \\
\hline \multicolumn{6}{|c|}{ Ethyl isobutyrate (1) + 1-butanol (2) at $p=40.000 \mathrm{kPa}$} \\
\hline 366.80 & 0.0000 & 0.0000 & & & \\
\hline 364.76 & 0.0737 & 0.1545 & 1.537 & 1.002 & 0.033 \\
\hline 363.40 & 0.1035 & 0.2114 & 1.507 & 1.004 & 0.046 \\
\hline 361.75 & 0.1719 & 0.3229 & 1.442 & 1.011 & 0.072 \\
\hline 360.13 & 0.2528 & 0.4220 & 1.370 & 1.025 & 0.098 \\
\hline 359.15 & 0.3083 & 0.4804 & 1.324 & 1.039 & 0.113 \\
\hline 357.49 & 0.4238 & 0.5810 & 1.236 & 1.082 & 0.135 \\
\hline 356.58 & 0.5038 & 0.6330 & 1.183 & 1.125 & 0.143 \\
\hline 355.83 & 0.5960 & 0.7015 & 1.128 & 1.193 & 0.143 \\
\hline 355.27 & 0.6759 & 0.7509 & 1.087 & 1.273 & 0.134 \\
\hline 354.66 & 0.7601 & 0.8004 & 1.051 & 1.388 & 0.116 \\
\hline 354.45 & 0.8573 & 0.8643 & 1.020 & 1.578 & 0.082 \\
\hline 354.62 & 0.9344 & 0.9208 & 1.004 & 1.796 & 0.043 \\
\hline 354.57 & 0.9682 & 0.9635 & 1.001 & 1.918 & 0.022 \\
\hline 354.84 & 1.0000 & 1.0000 & & & \\
\hline \multicolumn{6}{|c|}{ Ethyl isobutyrate (1) +1 -butanol (2) at $p=101.325 \mathrm{kPa}$} \\
\hline 390.74 & 0.0000 & 0.0000 & & & \\
\hline 389.38 & 0.0653 & 0.1094 & 1.551 & 1.002 & 0.031 \\
\hline 388.35 & 0.0998 & 0.1730 & 1.505 & 1.005 & 0.045 \\
\hline
\end{tabular}


Table S4. Continuation.

\begin{tabular}{cccccc}
\hline$T / \mathrm{K}$ & $x_{1}$ & $y_{1}$ & $\gamma_{1}$ & $\gamma_{2}$ & $G^{\mathrm{E}} /(\mathrm{RT})$ \\
\hline 386.84 & 0.1802 & 0.2817 & 1.408 & 1.016 & 0.075 \\
385.68 & 0.2513 & 0.3622 & 1.333 & 1.032 & 0.096 \\
385.10 & 0.3182 & 0.4193 & 1.272 & 1.051 & 0.111 \\
384.02 & 0.4215 & 0.5007 & 1.192 & 1.093 & 0.125 \\
383.40 & 0.5116 & 0.5806 & 1.135 & 1.141 & 0.129 \\
383.07 & 0.5893 & 0.6370 & 1.095 & 1.193 & 0.126 \\
382.81 & 0.6827 & 0.7054 & 1.057 & 1.270 & 0.113 \\
382.54 & 0.7591 & 0.7671 & 1.033 & 1.348 & 0.096 \\
382.49 & 0.8571 & 0.8547 & 1.012 & 1.470 & 0.065 \\
382.70 & 0.9030 & 0.8929 & 1.005 & 1.538 & 0.047 \\
383.00 & 0.9664 & 0.9624 & 1.001 & 1.644 & 0.017 \\
383.59 & 1.0000 & 1.0000 & & & \\
\hline${ }_{\text {Standard uncrtainties } u \text { are } u(T)}$ & $0.1 \mathrm{~K}, u(p)=0.1 \mathrm{kPa} u\left(x_{1}\right)=0.002$, and $u\left(y_{1}\right)=0.002$
\end{tabular}

${ }^{a}$ Standard uncertainties $u$ are $u(T)=0.1 \mathrm{~K}, u(p)=0.1 \mathrm{kPa}, u\left(x_{1}\right)=0.002$, and $u\left(y_{1}\right)=0.002$. 
Table S5. Parameters of Antoine's equation for vapour pressures of the pure compounds (pressure in $\mathrm{kPa}$, temperature in $\mathrm{K}$ ).

\begin{tabular}{ccccc}
\hline Compound & Reference & $A$ & $B$ & $C$ \\
\hline Ethyl isobutyrate & {$[17]$} & 6.42839 & 1509.7627 & -42.134 \\
Methanol & {$[70]$} & 7.20519 & 1581.993 & -33.439 \\
Ethanol & {$[70]$} & 7.16879 & 1552.601 & -50.731 \\
1-Propanol & {$[70]$} & 6.87613 & 1441.705 & -74.291 \\
1-Butanol & {$[70]$} & 6.54743 & 1338.769 & -96.108 \\
\hline
\end{tabular}




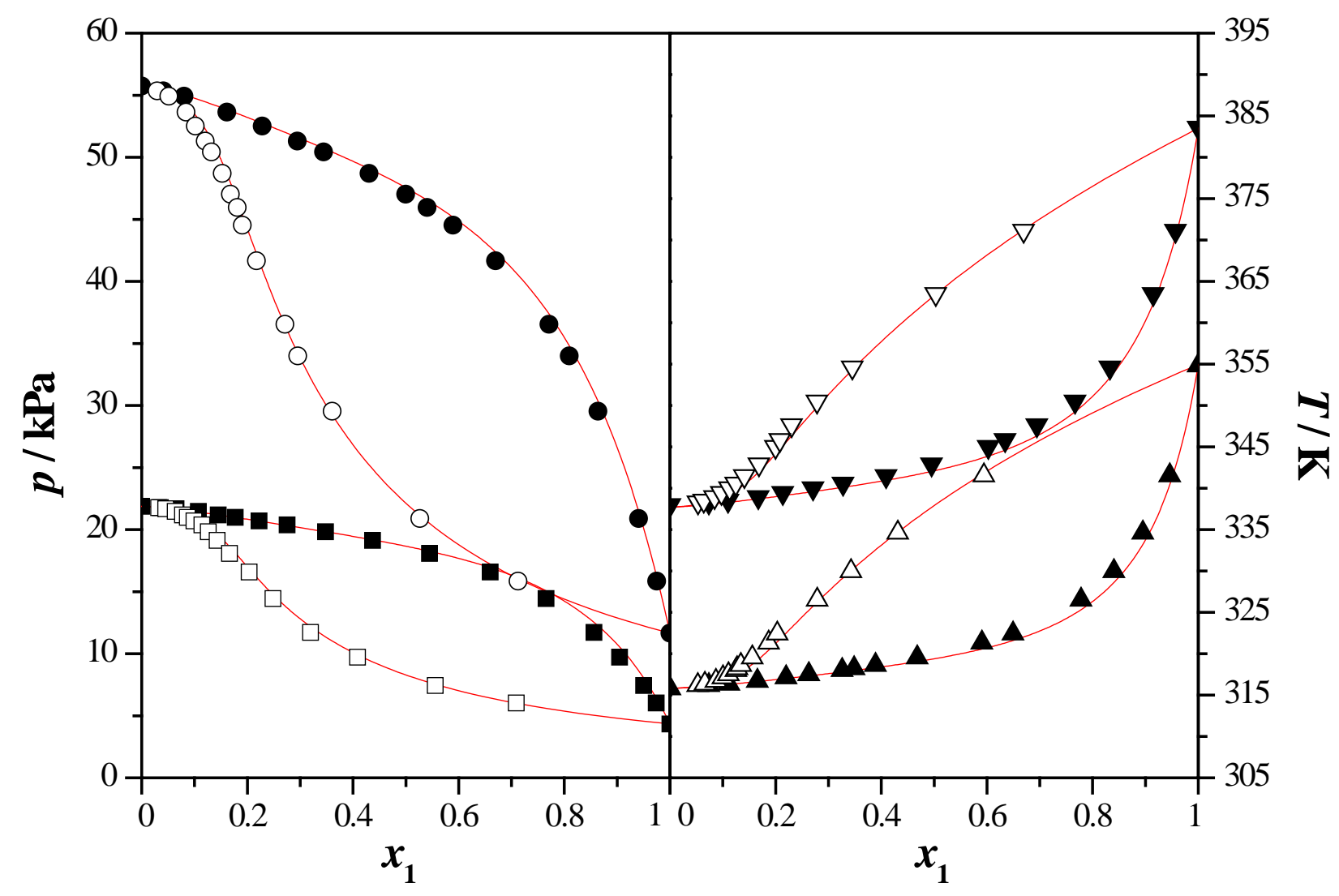

Fig. S1. $p-x_{1}-y_{1}$ and $T-x_{1}-y_{1}$ diagrams for the binary mixture ethyl isobutyrate (1) + methanol (2): $(\boldsymbol{\square}, \square)$ experimental data at $T=303.15 \mathrm{~K}$; $(\mathbf{O}, \bigcirc)$ experimental data at $T=323.15 \mathrm{~K}$; $(\boldsymbol{\Delta}, \triangle)$ experimental data at $p=40.000 \mathrm{kPa} ;(\boldsymbol{\nabla}, \nabla)$ experimental data at $p=101.325 \mathrm{kPa}$; $(-)$ UNIFAC prediction. 


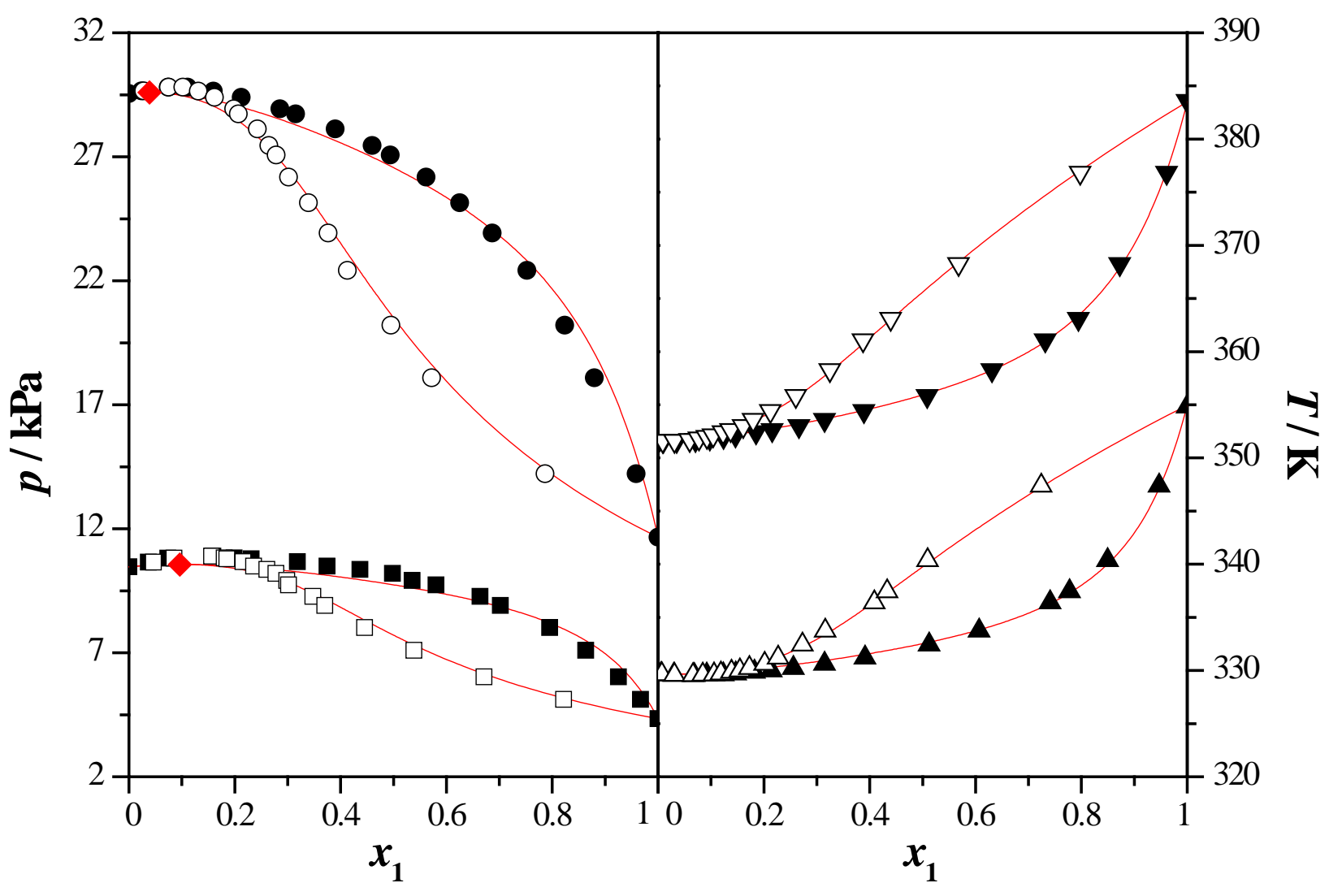

Fig. S2. $p-x_{1}-y_{1}$ and $T-x_{1}-y_{1}$ diagrams for the binary mixture ethyl isobutyrate (1) + ethanol (2): $(\boldsymbol{\square}, \square)$ experimental data at $T=303.15 \mathrm{~K} ;(\boldsymbol{\bullet}, \bigcirc)$ experimental data at $T=323.15 \mathrm{~K}$; $(\boldsymbol{\Delta}, \triangle)$ experimental data at $p=40.000 \mathrm{kPa} ;(\boldsymbol{\nabla}, \nabla)$ experimental data at $p=101.325 \mathrm{kPa}$; $(\diamond)$ UNIFAC predicted azeotropes; $(-)$ UNIFAC prediction. 


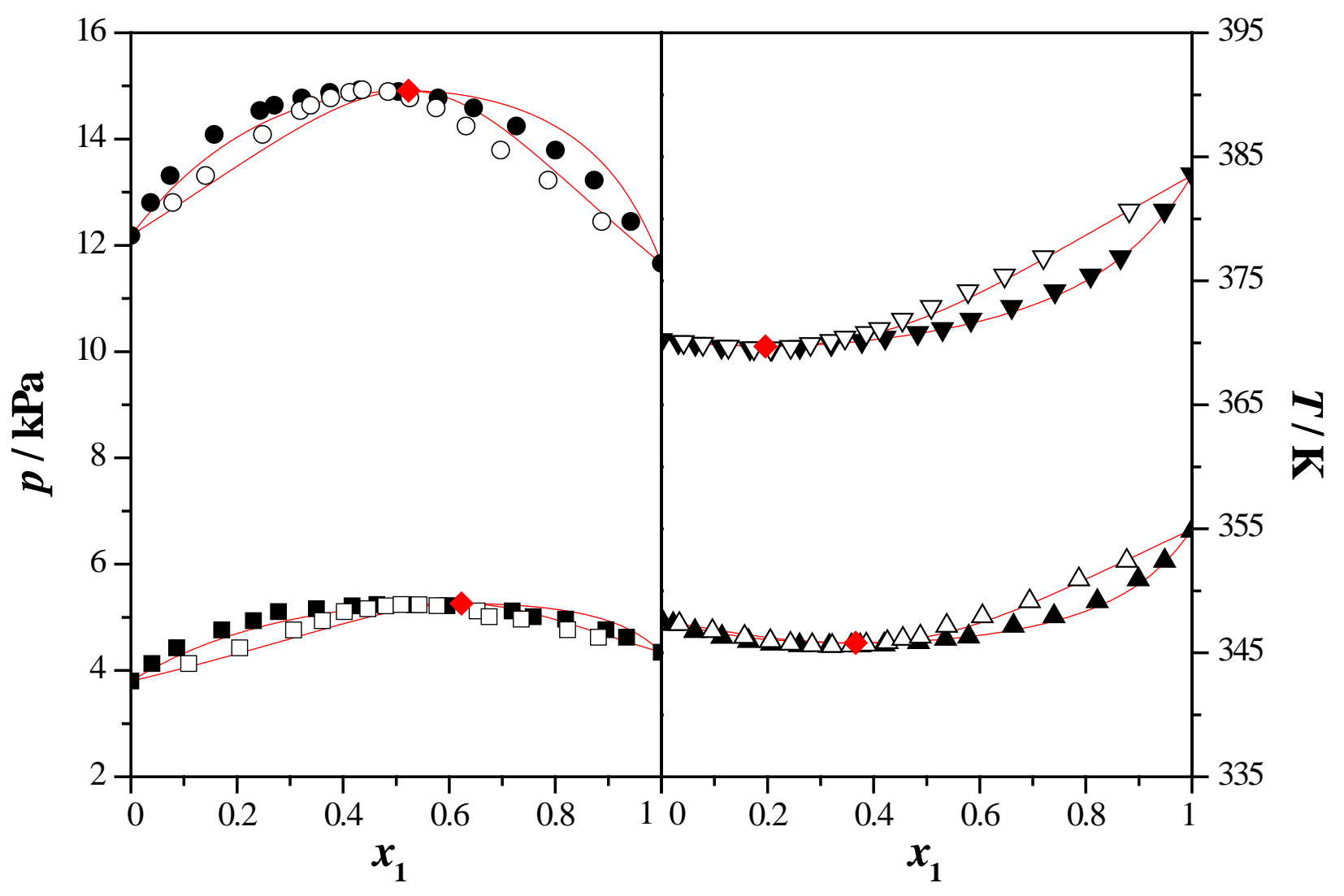

Fig. S3. $p-x_{1}-y_{1}$ and $T-x_{1}-y_{1}$ diagrams for the binary mixture ethyl isobutyrate (1) $+1-$ propanol (2): $(\boldsymbol{G}, \square)$ experimental data at $T=303.15 \mathrm{~K}$; $(\boldsymbol{\bullet}, \bigcirc)$ experimental data at $T=$ $323.15 \mathrm{~K} ;(\boldsymbol{\Delta}, \triangle)$ experimental data at $p=40.000 \mathrm{kPa} ;(\boldsymbol{\nabla}, \nabla)$ experimental data at $p=$ $101.325 \mathrm{kPa} ;(\diamond)$ UNIFAC predicted azeotropes; (-) UNIFAC prediction. 


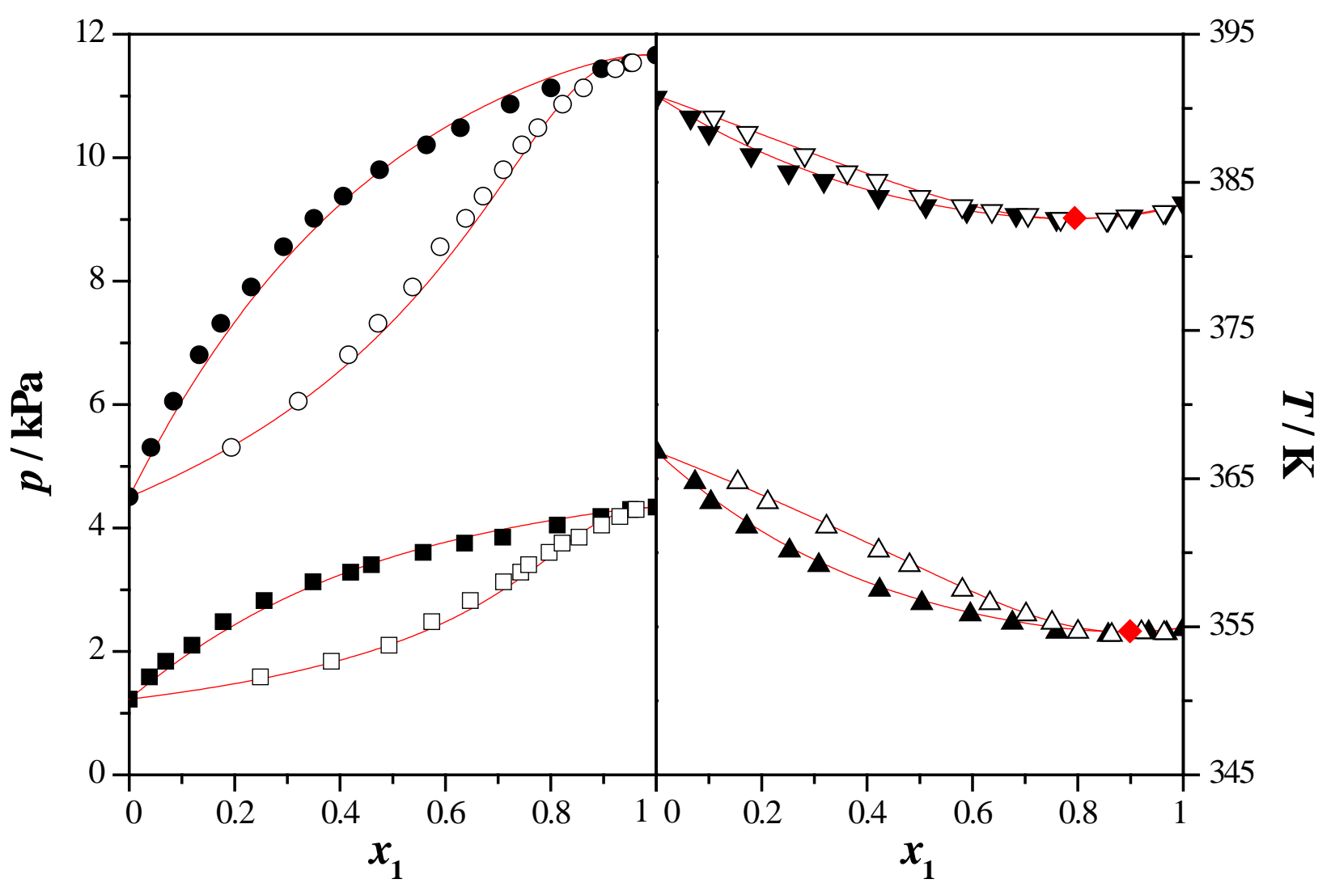

Fig. S4. $p-x_{1}-y_{1}$ and $T-x_{1}-y_{1}$ diagrams for the binary mixture ethyl isobutyrate (1) + 1-butanol (2): $(\boldsymbol{\square}, \square)$ experimental data at $T=303.15 \mathrm{~K} ;(\boldsymbol{\bullet}, \bigcirc)$ experimental data at $T=323.15 \mathrm{~K}$; $(\boldsymbol{\Delta}, \triangle)$ experimental data at $p=40.000 \mathrm{kPa} ;(\boldsymbol{\nabla}, \nabla)$ experimental data at $p=101.325 \mathrm{kPa}$; $(\diamond)$ UNIFAC predicted azeotropes; $(-)$ UNIFAC prediction. 